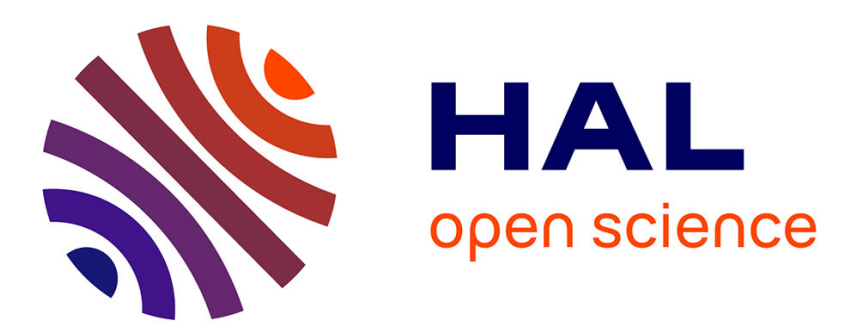

\title{
Le réseau viaire antique du Tricastin et de la Valdaine: relecture des travaux anciens et données nouvelles
}

Cécile Jung

\section{To cite this version:}

Cécile Jung. Le réseau viaire antique du Tricastin et de la Valdaine: relecture des travaux anciens et données nouvelles. Revue archéologique de Narbonnaise, 2009, 42, pp.85-113. 10.3406/ran.2009.1785 . hal-00598526

\section{HAL Id: hal-00598526 \\ https://hal.science/hal-00598526}

Submitted on 7 Jun 2011

HAL is a multi-disciplinary open access archive for the deposit and dissemination of scientific research documents, whether they are published or not. The documents may come from teaching and research institutions in France or abroad, or from public or private research centers.
L'archive ouverte pluridisciplinaire HAL, est destinée au dépôt et à la diffusion de documents scientifiques de niveau recherche, publiés ou non, émanant des établissements d'enseignement et de recherche français ou étrangers, des laboratoires publics ou privés. 


\title{
Le réseau viaire antique du Tricastin et de la Valdaine : relecture des travaux anciens et données nouvelles
}

\author{
Cécile Jung
}

\begin{abstract}
Résumé: À partir de travaux de carto-interprétation, de sondages archéologiques et de collectes de travaux anciens, le tracé de la voie d'Agrippa entre Montélimar et Orange est ici repris et discuté. Par ailleurs, l'analyse des documents planimétriques (cartes anciennes et photographies aériennes) et les résultats de plusieurs opérations archéologiques permettent de proposer un réseau de chemins probablement actifs dès l'Antiquité.

Mots-clés: voie d'Agrippa, vallée du Rhône, analyse cartographique, centuriation B d'Orange, itinéraires antiques.

Abstract: The layout of the Via Agrippa, between Montélimar and Orange, is studied and discussed in this article. Results presented are based mainly on map-interpreting, archeological surveys and aerial photos, which allow us to propose a road network already active during the Roman Period.
\end{abstract}

Keywords: via Agrippa, Rhône valley, cartography analysis, Orange B centuriation, roman roads.

Les travaux sur le réseau viaire antique en Tricastin et Valdaine se sont concentrés jusqu'à présent sur deux itinéraires : la voie d'Agrippa (Vallentin 1880 ; Sautel 1957 ; Boisse 1968 ; Salviat 1985) et un chemin reliant les oppida dans l'arrière-pays (Chapotat 1981). Dans le cadre d'une thèse sur la structuration du paysage du Tricastin depuis l'Antiquité (Jung 1999), j'ai rouvert le dossier de la voirie antique de cette région et essayé de le mettre à jour en travaillant non seulement sur le tracé des chemins déjà reconnus mais également sur le réseau routier, dans son ensemble, à partir de documents planimétriques, épigraphiques et archéologiques. Les résultats présentés ici sont issus de ce travail finalisé en 1999.

Les données concernant le tracé de la voie d'Agrippa entre Montélimar et Orange sont très disparates. Elles sont pour la plupart très générales bien que certaines aient fait l'objet d'un article très pointu sur un détail du parcours de la voie (Salviat 1985). L'ensemble des travaux publiés ont été repris en détail et rediscutés. J'expose ici une synthèse critique de ces études et fais une proposition actualisée du tracé de cette voie, à la lumière des données archéologiques récentes et des nouvelles observations sur les documents planimétriques.

J'ai appréhendé le réseau routier du Tricastin et de la Valdaine de manière globale, grâce à une analyse morphologique du réseau viaire des cartes d'Etat Major du XIX ${ }^{\mathrm{e}}$ s. Un tissu de voies secondaires, probablement antiques, et jusqu'à présent inconnu, a été mis en évidence. Celui-ci est constitué de nombreux itinéraires locaux ou régionaux qui permettent de raisonner sur les relations qu'entretiennent, entre eux, les centres de peuplements et de cerner les couloirs de circulations les plus importants. La présentation et l'analyse de ce réseau fera l'objet de la deuxième partie de mon propos.

\section{UN AXE NORD-SUD MAJEUR : LA VOIE D'AGRIPPA}

La voie d'Agrippa constitue la principale voie terrestre nord-sud. Entre Valence et Orange, elle reprend probablement le tracé d'un itinéraire plus ancien, évoqué par Strabon (Géographie, IV, I, 11), qui passait par Arausio, Aeria (oppidum de Barry?, commune de Bollène) et Valentia. Le tracé de la voie d'Agrippa est connu dans ses grandes lignes grâce aux travaux de Florian Vallentin (Vallentin 1880). Cet érudit a déduit son tracé en recensant les milliaires trouvés sur la rive gauche du Rhône et en identifiant les stations citées par les sources antiques - Table de Peutinger, Itinéraire de Bordeaux à Jérusalem (ou Itinéraire Hiersolymitain daté de 333 ap. J.-C.) et Cosmographie de l'Anonyme de Ravène - avec des lieux- 
dits actuels. Les données fournies dans la Cosmographie de l'anonyme de Ravenne, probablement rédigée au haut Moyen Âge, sont une compilation des sources antiques. Elles correspondent ici à celles de la Table de Peutinger et offrent peu d'intérêt (fig. 1).

L'itinéraire de Bordeaux à Jérusalem est le plus détaillé puisqu'il donne non seulement le nom des stations, les distances entre elles mais également leur statut. Il indique entre Valence et Orange, quatre mutationes: Umbenno (Les Battendons, commune d'Etoile), Bantiana (Banse, commune de Saulce), Novem Craris (Le Logis de Berre, commune des Granges-Gontardes), Senomagos/Ad Letoce (Saint-Pierre de Senos, commune de Bollène et le franchissement du Lez à Bollène) et une mansio : Acunum (Montélimar).

Neuf milliaires ont été retrouvés le long de la voie entre Valence et Orange, le plus ancien est dédié à Tibère (CIL, XVII, 165), les autres concernent des empereurs du bas Empire (Aurélien (CIL, XVII, 160, 164), Constantin
(CIL, XVII, 163, 166) Antonin le Pieux (CIL, XVII, 161), Dalmatius (CIL, XVII, 163a). Claude Boisse, qui s'est également intéressé au tracé de la voie d'Agrippa, signale la découverte de deux bornes anépigraphiques, entre Malataverne et le Logis de Berre. Elles sont distantes entre elles d'un mille et pourraient, d'après lui, pérenniser l'emplacement d'anciens milliaires (Boisse 1968 : 110).

Si le tracé de la voie d'Agrippa est connu dans ses grandes lignes sur l'ensemble de son parcours, grâce à l'identification de la plupart des stations qui la jalonnent, il n'en va pas de même en ce qui concerne le détail de son itinéraire. En effet, la grande majorité des auteurs ayant représenté le tracé de cette voie ont relié en ligne droite les stations connues; la carte dressée par Jacques Sautel dans la Carte archéologique de la Gaule romaine du département de la Drôme en est un parfait exemple (Sautel 1957). Aussi, l'ensemble du tracé de cette voie peut être repris et affiné.

\begin{tabular}{|c|c|c|c|c|c|c|c|c|}
\hline \multicolumn{3}{|c|}{ Table de Peutinger } & \multicolumn{3}{|c|}{$\begin{array}{c}\text { Itinéraire de Bordeaux à } \\
\text { Jérusalem }\end{array}$} & \multirow{2}{*}{$\begin{array}{c}\text { Anonyme de Ravenne } \\
\text { Noms des stations }\end{array}$} & \multicolumn{2}{|c|}{ Actuel } \\
\hline $\begin{array}{c}\text { Noms des } \\
\text { stations }\end{array}$ & \begin{tabular}{|l} 
Distance \\
en milles
\end{tabular} & $\begin{array}{c}\text { Conversion } \\
\text { en } \mathrm{km}\end{array}$ & $\begin{array}{c}\text { Noms des } \\
\text { stations }\end{array}$ & \begin{tabular}{|c|}
$\begin{array}{c}\text { Distance en } \\
\text { milles }\end{array}$ \\
\end{tabular} & $\begin{array}{c}\text { Conversion } \\
\text { en } \mathrm{km}\end{array}$ & & $\begin{array}{l}\text { lieudits sur } \\
\text { I.G.N. }\end{array}$ & \begin{tabular}{|l} 
Distance \\
sur I.G.N.
\end{tabular} \\
\hline Batiana-Acunum & XII & 17,78 & $\begin{array}{l}\text { Bantianis- } \\
\text { Acunum }\end{array}$ & XII & 17,78 & Untiana-Acunon & $\begin{array}{l}\text { Banse (commune } \\
\text { de Saulce) } \\
\text { Montélimar }\end{array}$ & 18 \\
\hline $\begin{array}{l}\text { Acunum- } \\
\text { Senomago }\end{array}$ & XVIII & 25,66 & & & & Acunon-Bonomago & $\begin{array}{l}\text { Montélimar-Saint } \\
\text { Pierre-de-Senos } \\
\text { (commune de } \\
\end{array}$ & 27 \\
\hline & & & $\begin{array}{l}\text { Acunum- } \\
\text { Novem } \\
\text { Craris }\end{array}$ & \begin{tabular}{|c|}
$\mathrm{XV}$ \\
(manuscrit de \\
$\mathrm{X}$ \\
(manuscrit de \\
Vérone) \\
\end{tabular} & $\begin{array}{r}22,22 \\
14,8\end{array}$ & & $\begin{array}{l}\text { Montélimar- } \\
\text { Logis-de-Berre } \\
\text { (commune des } \\
\text { Granges- } \\
\text { Gontardes) }\end{array}$ & 15 \\
\hline & & & $\begin{array}{l}\text { Novem } \\
\text { Craris- } \\
\text { Ad Letoce }\end{array}$ & $\begin{array}{c}\mathrm{X} \text { (manuscrit } \\
\text { de Paris) }\end{array}$ & 14,8 & & $\begin{array}{l}\text { Logis-de-Berre } \\
\text { (commune des } \\
\text { Granges- } \\
\text { Gontardes)-le } \\
\text { Lez commune de } \\
\text { Bollène }\end{array}$ & 15 \\
\hline $\begin{array}{l}\text { Senomago- } \\
\text { Arausione }\end{array}$ & $\mathrm{XV}$ & 22,2 & & & & Bonomago-Arasione & $\begin{array}{l}\text { Saint-Pierre-de- } \\
\text { Senos (commune } \\
\text { de Bollène)- } \\
\text { Orange }\end{array}$ & 18,5 \\
\hline & & & $\begin{array}{l}\text { Ad Letoce- } \\
\text { Arausione }\end{array}$ & \begin{tabular}{|c|} 
XIII \\
(manuscrit de \\
Paris)
\end{tabular} & 19,26 & & $\begin{array}{l}\text { Le Lez commune } \\
\text { de Bollène- } \\
\text { Orange }\end{array}$ & 16,5 \\
\hline
\end{tabular}

Fig I :Tableau des distances entre mutationes données par les itinéraires antiques. 


\subsection{De Montélimar (Acunum) au ruisseau de la Riaille}

\subsubsection{Le parcours proposé}

À Montélimar, on situe traditionnellement la voie d'Agrippa à l'emplacement de la Grande-Rue, où, lors de travaux effectués au début du siècle, des dalles de cette chaussée antique auraient été découvertes (Sautel 1957 : 39). Cette rue nord-sud relie la porte Saint-Martin, au nord, à la porte d'Aygu, au sud. Au nord de la porte SaintMartin, les vestiges de la voie d'Agrippa bordée d'un aqueduc ont été reconnus par Claude Boisse en 1961. Au sud de la porte d'Aygu, autour de l'ancienne église de Notre-Dame-d'Aygu, une nécropole du bas Empire et du haut Moyen Âge a été mise en évidence lors de fouilles, ce qui laisse supposer la proximité du passage de la voie. La Grande-Rue qui relie ces deux portes a donc toutes les chances de pérenniser la chaussée antique, cependant son tracé sinueux cache certainement une histoire plus complexe (fig. 2).

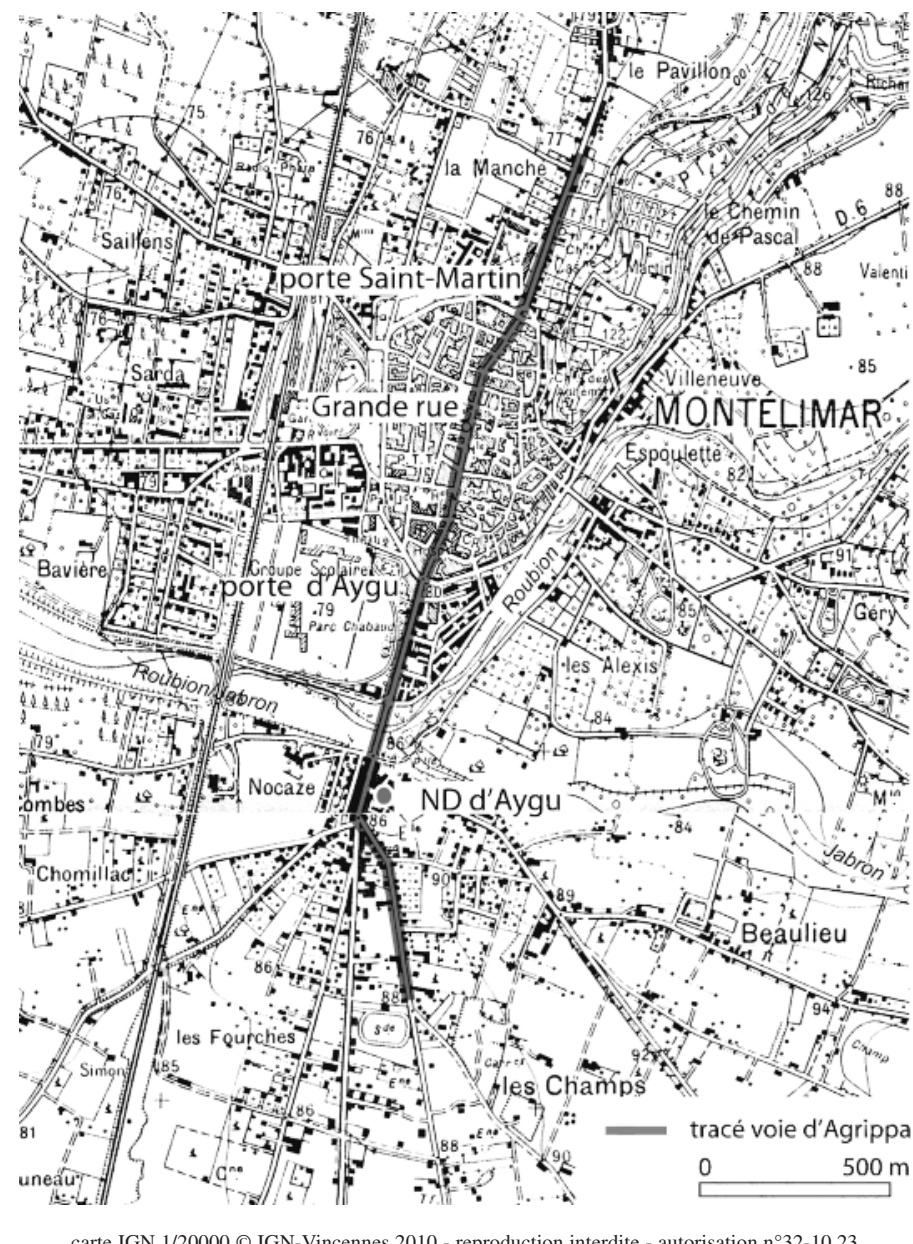

Fig. 2 :Tracé de la voie d'Agrippa à Montélimar (fond IGN I/20000 levé 195I ; Jung, 2008).
Certains ont voulu identifier le faubourg d'Aygu avec la mansio Acunum. Si la proximité étymologique Aygunum-Acunum apparaît sans conteste, l'identification archéologique est plus discutable. Les vestiges archéologiques connus dans le quartier d'Aygu sont ceux d'une nécropole, ce qui renvoie plutôt à la localisation d'un faubourg qu'à celle d'une agglomération. Sous l'actuelle ville de Montélimar, les vestiges sont abondants et révèlent en revanche l'existence d'un habitat. Le toponyme Aygu indique plus probablement la proximité de l'agglomération antique que sa localisation exacte. Par ailleurs, la position topographique du quartier, sur la rive sud du RoubionJabron, permet d'envisager ce secteur comme un faubourg contrôlant, au sud, le passage des rivières.

Il est difficile de savoir comment se faisait la traversée du Roubion-Jabron à l'époque antique. On sait qu'en 1386, une très grosse crue déporte le cours du Roubion au sud au-delà des arches de l'ancien pont, qui, désaffecté, servit dès lors de carrière de pierres pour la réfection des fortifications de la ville de Montélimar (Cartulaire de Montélimar, XCVI). Michèle Bois pense que ce pont détruit correspondait au pont romain qui permettait à la voie d'Agrippa de franchir le confluent du Roubion-Jabron (Bois 1993, vol. I : 34, vol. III : 78). Aucun élément ne permet néanmoins d'attester cette hypothèse. S'il paraît plus logique que le franchissement de cet important cours d'eau au débit irrégulier devait se faire au moyen d'un pont plutôt que d'un gué, aucun élément ne nous permet de l'affirmer. Cependant, on peut avancer que le passage obligé pour traverser le Roubion et le Jabron afin d'entrer à Montélimar devait se trouver au faubourg d'Aygu, à la confluence des deux rivières comme en témoigne l'importante patte d'oie que forment les neufs chemins au sud du faubourg (fig. 2 et 3).

Il est difficile de déterminer le passage exact de la voie d'Agrippa à la périphérie sud de Montélimar, cette zone étant désormais totalement urbanisée ; les documents planimétriques récents ne nous apportent aucune information. Il semblerait, d'après ce que l'on peut connaître du tracé de la voie plus au sud, qu'il faille chercher son passage à proximité de «l'Ancienne Grande Route» ou «Chemin de Montélimar à Saint-Paul-Trois-Châteaux », désignés ainsi sur le cadastre napoléonien et aujourd'hui rebaptisée départementale D. 206 (fig. 3).

Plus au sud, au niveau du château « le Perchoir », sur la carte I.G.N. au 1/25 000, un chemin vicinal suit le piémont des collines d'Allan à la hauteur de la courbe de niveau des $125 \mathrm{~m}$ (fig. 3). Ce chemin, goudronné dans sa partie nord, disparaît, au sud du lieu-dit le « Devès », dans le «Bois de Ferrotin », toponyme dérivé de Ferré, qui peut rappeler le passage d'une voie ancienne. On peut néanmoins imaginer son prolongement en suivant, dans la partie boisée, la courbe de niveau des $125 \mathrm{~m}$. La limite 
entre les cultures et le boisement, juste au sud, peut pérenniser le tracé de la voie antique avant de réapparaître, au niveau du lieu-dit le « Conquet », sous la forme d'un chemin de terre que l'on suit jusqu'à la Riaille. Sur les cartes au 1/20 000 ou sur la carte d'Etat Major révisée au $1 / 50000$, ce chemin est en activité depuis le château « le Perchoir » jusqu'au ruisseau de la Riaille. Sur la carte de Cassini, le toponyme «La Borne », indiqué au passage de la Riaille, peut également rappeler le passage d'une voie antique. Les indices topographiques et toponymiques permettent d'envisager le tracé de la voie sur les piémonts des hautes terrasses du Rhône et les vestiges archéologiques donnent également corps à cette hypothèse. Ainsi, dans les années 1960, M.-C Latarche a fouillé, lors des travaux liés à la construction de l'autoroute A.7, au niveau

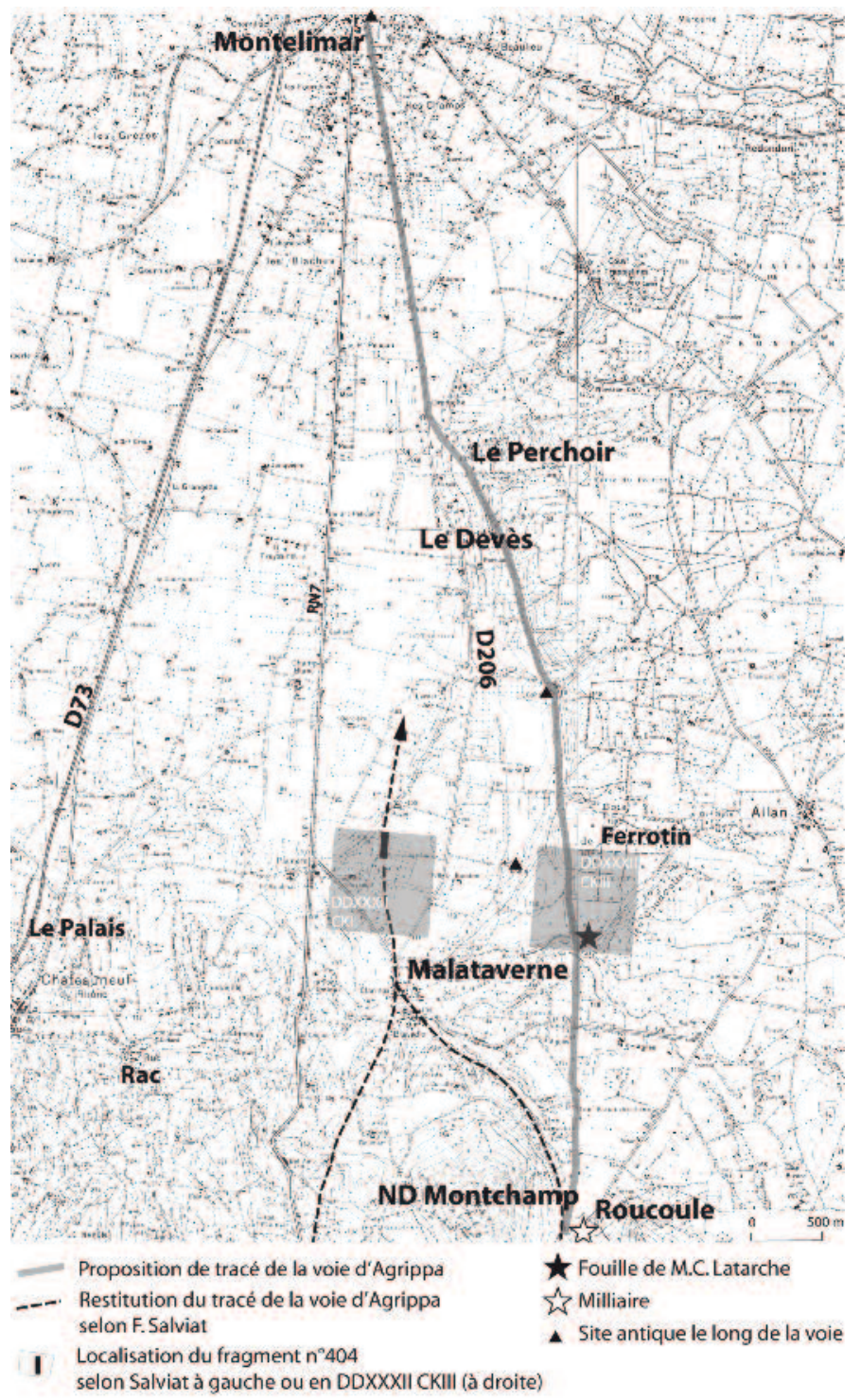

carte IGN 1/20000 @ IGN-Vincennes 2010 - reproduction interdite - autorisation n³2-10.23

Fig 3 :Tracé de la voie d'Agrippa au sud de Montélimar (fond IGN I/20000 levé 195I ; Jung, 2007). du franchissement de la Riaille, un bâtiment de 22 x 7,5 m bordé d'une voie, qu'il a identifiée comme étant la voie d'Agrippa. La fonction première du bâtiment édifié au III ${ }^{\mathrm{e}}$ s., aurait été celle d'un relais flanqué d'une grangeentrepôt puis, au $\mathrm{IV}^{\mathrm{e}} \mathrm{s}$., après un réaménagement, celle d'un cellier et d'un atelier de vinification (Tourrenc 1971 : 434-435). La voie découverte de M.-C. Latarche coïncide avec le passage de celle décrite précédemment et son tracé s'inscrit dans la continuité de celui reconnu, plus au sud sur les photographies aériennes et par la découverte d'une borne milliaire au XIX ${ }^{\mathrm{e}}$ s. (fig. 3).

\subsubsection{Discussion des données anciennes}

Le tracé que je propose entre Montélimar et la Riaille a jusqu'à présent été ignoré par les chercheurs qui se sont penchés sur la question. Seul, Claude Boisse avait repéré le fait, pour la partie au sud de la Riaille : «Un tronçon rectiligne part effectivement du pied de Montchamp coupant la Riaille perpendiculairement au levant de Malataverne » (Boisse 1968 : 107). Ce tronçon, si nous l'avons bien restitué, correspond à la suite du tracé que nous venons de proposer, mais l'auteur ne le continue pas au nord de la Riaille. Il lui préfère, en effet, un tracé plus à l'ouest, qui reprend celui de la départementale D. 206, depuis Montélimar jusqu'au village de Malataverne (fig. 3).

Jacques Sautel reste très évasif sur ce tronçon et semble mélanger les lieux : De Montélimar la voie romaine se dirigeait vers le sud, soit par la bordure des collines qui surplombe la plaine de Bondonneau (commune d'Allan), soit directement comme la Route Nationale $n^{\circ} 7$ vers le col de Malataverne et Rac (commune de Châteauneuf-du-Rhône) : borne milliaire, vestiges du quartier du Palais (Sautel 1957 : 112).

La première des solutions qu'il envisage correspond à celle la plus fréquemment énoncée : le tracé de la départementale D. 206.

La seconde est plus surprenante et reflète une série d'erreurs. Tout d'abord le tracé qu'il propose correspond à celui de la R.N. 7, mis en service au XVIII' ${ }^{\text {s }}$. pour doubler l'ancien « chemin royal » (aujourd'hui R.D. 73), qui passait depuis Montélimar par Châteauneuf-du-Rhône avant de gagner Donzère et Pierrelatte. Jacques Sautel associe à la R.N. 7 le site du Palais (commune de Châteauneuf-duRhône), qui se trouve en fait le long de l'ancien chemin royal (actuelle D. 73), et surtout il commet une autre erreur en replaçant le long de cet axe le milliaire trouvé sur le territoire de la commune de Malataverne. Cette méprise s'explique facilement puisque lors de la découverte de ce milliaire, dans le courant du XIX ${ }^{\mathrm{e}}$ s., le cheflieu de commune n'était pas Malataverne mais Rac, situé à l'ouest du terroir. Jacques Sautel a donc replacé la borne à l'ouest de la commune alors que Florian Vallentin rapporte 
que celle-ci fut retrouvée «entre Roucouls et Montchamp, près de l'emplacement de la voie romaine " (Vallentin 1880 : 388) collines situées beaucoup plus à l'est.

Cette même erreur a été commise par François Salviat (Salviat 1985 : 281) qui écrit : "Le passage de la voie antique à partir de Montélimar-Acunum et en direction de Novem Craris, (...) était déjà jalonné approximativement par la découverte à Rac, à $8 \mathrm{~km}$ au sud de Montélimar d'un milliaire de Tibère qui mentionne une réfection en 31/32 ap. J.C. ». Cette situation erronée de la découverte du milliaire lui permet d'argumenter sa proposition de localisation d'un fragment des marbres d'Orange, le fragment 404, entre la R.N.7 et la D. 206 sur lequel nous allons revenir. Cependant, il reste lui aussi très évasif sur le tracé entre Malataverne et Montélimar. Pour lui la R.N. 7 est trop à l'ouest, et la départementale D. 206, proposée aussi par Guy Barruol (Barruol 1972 : 991), ne correspond pas non plus totalement au tracé antique. Il conclut alors sur ces mots : «La chaussée antique suivait peut-être un trajet original ».

Le fragment de marbre $n^{\circ} 404$ des documents cadastraux d'Orange brouille également la vision que l'on peut avoir du passage de la voie dans ce secteur. Il s'agit d'un morceau de plaque mutilé où sont gravées deux lignes parallèles écartées de $0,0075 \mathrm{~m}$, interprétées comme étant une route et probablement la voie d'Agrippa, seule voie à être représentée sur la forma. La localisation de ce fragment de marbre a fait l'objet d'un article de François Salviat (Salviat 1985), que nous devons rediscuter.

Il présente une inscription fragmentaire qui rend son attribution et sa localisation délicate. On peut lire les coordonnées : ...(X)XII CK I. Seul le cadastre B possède un decumanus DD XXII, ce qui laisse supposer que ce fragment appartient à ce réseau. André Piganiol (Piganiol 1962) a classé ce fragment dans les fragments d'attribution incertaine et propose à titre d'hypothèse sa localisation en DD XXXII CK I de la plaque III L (fig. 4), mais est gêné par l'écriture toute différente que l'on rencontre sur les autres fragments connus à proximité. François Salviat (Salviat 1985 : 278) reprend cette localisation et écarte le problème de l'écriture qu'il considère très variable dans le cadastre B, remarque qu'avait aussi faite André Piganiol dans son ouvrage et qui, selon François Salviat, «ne doit pas constituer un obstacle».

Le problème demeure complexe car cette localisation correspond à un secteur où l'on possède très peu de fragments qui puissent permettre d'attester son emplacement. En effet, les restitutions théoriques de la forma émises par André Piganiol proposent dans ce secteur la présence de deux plaques, III K et III L, dont on ne connaît pas les limites ni l'existence véritable. Cette hypothèse est simplement induite par la surface, suffisante pour deux plaques. Seuls des fragments du coin sud-est de DD XXI
CK III à DD XXV CK III ont été localisés et attribués à la plaque III K. Cette plaque présente les mêmes caractéristiques que celle du fragment 404 en ce qui concerne l'épaisseur $(0,019 \mathrm{~m})$ et le revers : layé à petite laie (ce sont les seuls fragments à présenter ce type de motif). Ces deux remarques peuvent induire leur appartenance à la même plaque, si ce n'est une écriture totalement différente qui demeure gênante au sein d'un même support. Il faudrait donc envisager deux plaques de mêmes caractéristiques mais gravées par deux mains différentes.

Le fragment 404 présente un joint à droite avec un trou de goujon qui indique un bord de plaque. Sa localisation est impossible en DD XXII CK I, la plaque III K allant au moins jusqu'à DD XXV, d'après les fragments retrouvés (fig. 4).

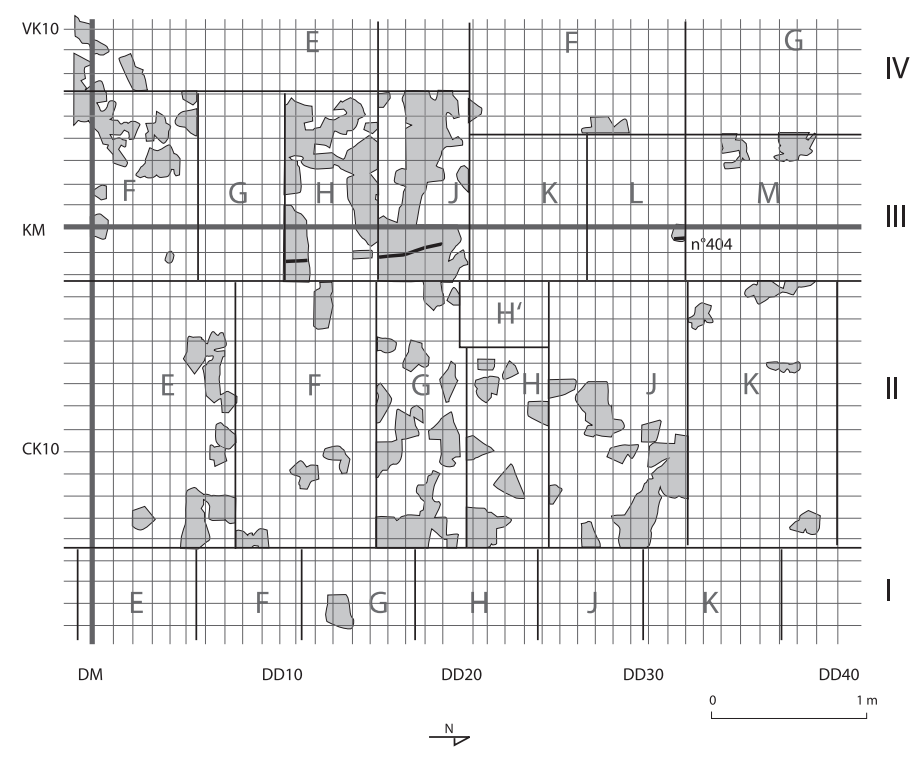

Fig 4 :Agencement des marbres du cadastre $B$ d'Orange et positionnement du fragment $n^{\circ} 402$ selon F. Salviat

(d'après Piganiol, 1962).

La localisation que proposent André Piganiol et François Salviat en DD XXXII CK I peut coïncider avec le bord nord de la plaque III L, que l'on peut supposer, s'il est dans la prolongation de ceux des plaques IV F et II J, en DD XXXII. Si la localisation au sein des marbres en DD XXXII CK I peut paraître satisfaisante, son report sur un fond de carte et sur le terrain l'est beaucoup moins. En effet, le tracé de la voie se retrouve à l'à-pic d'une des terrasses du Rhône, à proximité du lieu-dit Pozier, sur la commune de Malataverne, ce qui topographiquement parait surprenant (fig. 3) et qui ne coïncide pas avec les observations archéologiques de M.-C. Latarche situées plus à l'est. 
Que penser alors de la localisation du fragment 404, proposée par André Piganiol et François Salviat ? Il est en effet surprenant, contrairement aux autres marbres figurant la voie d'Agrippa, de ne pas pouvoir appliquer la réalité du terrain à la gravure antique. On peut alors songer à d'autres possibilités, mais aucune d'entre elles n'est plus satisfaisante.

On pourrait lire non pas DD XXXII CK I mais DD XXXXII CK I, mais on ne connaît pas de marbre au-delà de DD XXXX. Il faut cependant rappeler que les observations archéogéographiques effectuées par Gérard Chouquer (Chouquer 1994 : 1995) tendent à montrer que la centuriation d'Orange recouvrait le territoire de Montélimar, au-delà du decumanus DD XXXX. La centurie DD XXXXII CK I correspond à la colline surplombant à l'est Montélimar. Y placer la voie d'Agrippa est topographiquement improbable et archéologiquement peu envisageable. Elle est en effet traditionnellement reconnue dans la grande rue de Montélimar. Cette proposition de localisation peut donc difficilement être retenue.

Il faut également envisager que le chiffre attaché à la mention CK (citra kardinem) est incomplet. Lorsque l'on regarde le fragment, on s'aperçoit que le I de CK I est collé au bord de la plaque. Le graveur a pu ne représenter qu'une partie du chiffre sur cette ligne avant de l'achever sur la ligne suivante. On pourrait alors imaginer une localisation en DD XXXII CK III qui serait en adéquation avec la réalité archéologique. On connaît deux exemples, présentant des retraits à la ligne (un sur la plaque II K, l'autre sur la plaque IV D) ; mais dans les deux cas, c'est la totalité du chiffre qui est rejeté à la ligne.

Un autre problème se pose, si l'on considère qu'il s'agit de la centurie DD XXXII CK III. Cette centurie serait à cheval sur la plaque III L et IIJ (fig. 4). Le fragment 404 est mutilé mais vu sa hauteur conservée, on devrait observer la bordure de la plaque. Il paraît donc difficilement envisageable que le fragment 404 corresponde à la centurie DD XXXII CK III.

Le problème de l'identification du fragment 404 demeure donc d'actualité. L'hypothèse émise par André Piganiol et François Salviat n'est pas satisfaisante. Elle s'accorde à la logique architecturale des marbres, même si des réserves sur l'épigraphie demeurent, mais pas à la réalité du terrain. En revanche, la proposition de localisation en accord avec les données archéologiques est trop sujette à caution au niveau épigraphique et architecturale pour être validée. Ce fragment de marbre pose donc plus de problème qu'il n'aide à positionner le tracé de la voie d'Agrippa. Il est vraiment difficile d'envisager le passage de la chaussée au sein de la centurie DDXXX II CK I ; aucun linéament n'y pérennise la voie ou ne se prolongerait les centuries voisines et les données archéologiques relatives à son passage (borne milliaire, voie de Termini) ne sont compatible avec cette localisation. Pour l'heure, il faut, comme André Piganiol l'a fait, restituer ce morceau de marbre au lot des fragments dont l'attribution reste incertaine.

\subsection{De la Riaille au Logis de Berre (Novem Craris)}

\subsubsection{Tracé proposé}

Sur la rive sud de la Riaille, dans le prolongement de la fouille de M.-C. Latarche, la lecture des photos aériennes et des cartes antérieures aux travaux de l'autoroute révèle une continuité du tracé vers le sud. En effet, une limite de parcelle tout d'abord, puis un chemin semblent avoir fossilisé la trace de la voie antique (fig. 5). Il s'agit certainement

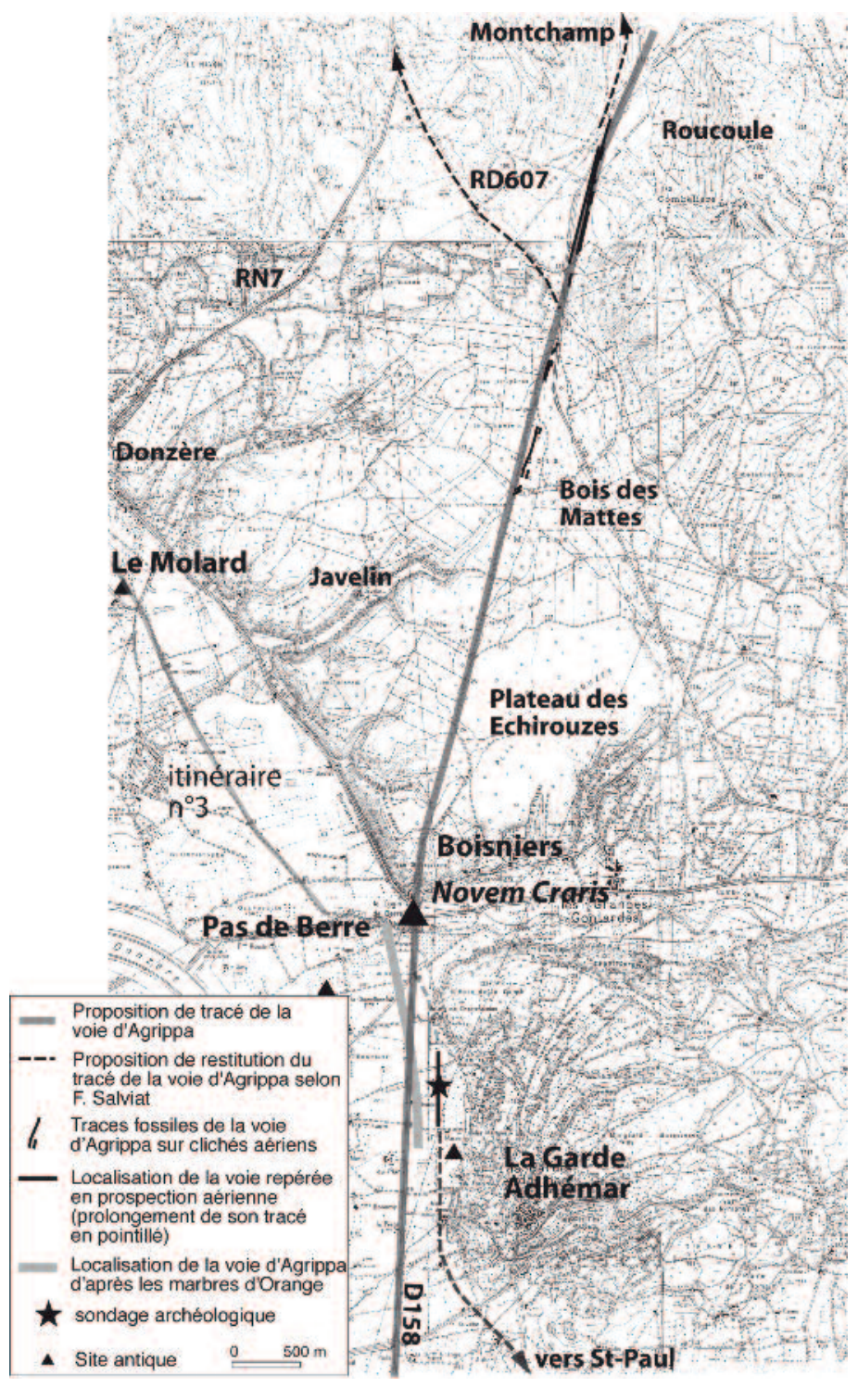

carte IGN 1/20000 @ IGN-Vincennes 2010 - reproduction interdite - autorisation n³2-10.23

Fig 5 :Tracé de la voie d'Agrippa dans le secteur du Logis de Berre (fond IGN I/20 000 levé 195 I ; Jung, 2007). 
du tronçon repéré par Claude Boisse dont nous avons parlé plus haut (Boisse 1968 : 107). Cette section de la voie arrive en droite ligne entre les collines de Montchamp et Roucoule où a été découvert le milliaire mentionné par Florian Vallentin. À partir de là, de nombreuses missions aériennes révèlent les traces fossilisées de la voie d'Agrippa, sous la forme d'une chaussée encadrée par de larges fossés, à quelques mètres à l'est d'un chemin de terre encore en activité sur la carte au 1/20 000. La photo tirée d'une mission alliée réalisée en 1944 (Cliché $n^{\circ} 3167$, mission 23 SF 351), que publie François Salviat dans son article, est certainement une des plus spectaculaires. Sur les missions plus récentes, après que le «Bois des Mattes » ait été défriché pour être planté en vigne, on suit, sur près de trois kilomètres la voie fossile. Elle est longée à l'ouest par un chemin de terre pérennisant le tracé du « grand chemin », appelé ainsi en 1701 et alors encore entretenu (Peloux, 1993: 96) (fig. 5). Sur le cadastre napoléonien, il figure sous le nom de «chemin dit ferré ou ancienne route de Bollène à Lyon ». On perd la trace fossile de la voie peu après la «Combe de l'Homme Mort ».

Lors des travaux archéologiques du TGV-Méditerranée les révélations de la voie sur les photographies aériennes nous ont permis de guider les sondages archéologiques afin de recouper la voie antique. Aucun vestige de la voie romaine n'a été retrouvé, hormis un hypothétique fond de fossé conservé sur $10 \mathrm{~cm}$. Les sous-solages réalisés lors de la plantation du vignoble ont perturbé les niveaux supérieurs de la stratigraphie. Néanmoins, il faut certainement considérer que, sur ces hautes terrasses rhodaniennes où les galets et les graviers affleurent en continu, aucune bande de roulement construite n'était nécessaire. Les fossés, visibles sur les photographies verticales, devaient être la seule matérialisation au sol de la voie, la chaussée étant constituée par le substrat quaternaire.

Au sud du plateau des Echirouzes, la voie empruntait l'étroite vallée des «Boisniers » pour descendre en droite ligne au Logis-de-Berre (Novem Craris).

\subsubsection{Discussion des données anciennes}

Si la partie méridionale de ce tronçon a été perçue de cette même manière par Claude Boisse et François Salviat, il n'en va pas de même pour le passage au nord de Notre-Dame-de-Montchamp. Tous les deux envisagent que le tracé de la voie fasse une grande courbe comme celle décrite par la R.N.7, afin de regagner le village de Malataverne, tracé qui devait correspondre à celui de l'ancien « grand chemin ».

Jean Benoît et François Salviat proposent quant à eux un autre tracé au sud de la colline de Montchamp, par l'actuelle départementale D. 607 (fig. 5). Celui-ci paraît peu probable, mais il concorde avec la position erronée du milliaire de Rac. François Salviat d'ailleurs ne défend que très peu cette proposition de tracé et insiste plus fortement sur le tracé nord.

Jacques Sautel, qui fait passer la voie d'Agrippa à l'emplacement de l'ancienne R.N.7, lui fait regagner le Logis de Berre par Donzère et la plaine de Pierrelatte. Le tracé dans la plaine correspond à un chemin antique, mis en évidence par Thierry Odiot, qui joignait le Logis de Berre à la villa du Molard avant de gagner Donzère (itinéraire ${ }^{\circ} 3$ ) (fig. 5 et 13).

Enfin, il faut signaler que la descente sur le Logis de Berre a pu s'effectuer par une autre combe que celle des «Boisniers », raide et étroite. En effet, de nombreuses combes entaillent le «Plateau des Echirouzes » : depuis Donzère jusqu'au Logis-de-Berre, on en dénombre pas moins de sept. De plus on observe, sur les photos aériennes, la trace fossile d'une voie qui part en direction de la vallée de pénétration de "Javelin », vallée large et peu pentue, certainement plus praticable que celle des «Boisniers ». Odette Peloux signale : «des textes du milieu $d u X V I I I^{e}$ siècle font état d'un passage de "voyageurs », de «troupes et de charrettes sur le chemin de Javelenc qui semble fonctionner comme déviation du chemin ferré, lequel présentait encore un trafic non négligeable " (Peloux 1993 : 96). Les traces observées rappellent celles visibles dans le « Bois des Mattes », une chaussée encadrée par des fossés, mais il est délicat de savoir s'il s'agit de la voie d'Agrippa ou de celle évoquée par les textes modernes.

Il faut donc retenir que le tracé de la voie d'Agrippa pour la montée au plateau des Echirouzes a pu présenter différents itinéraires, la combe des «Boisniers » ou celle de « Javelin ».

\subsection{Du Logis de Berre (Novem Craris) à Saint-Pierre- de-Senos (Senomago)}

La question du passage de la voie d'Agrippa dans ce secteur pose également des interrogations, surtout aux abords du Logis-de-Berre.

Traditionnellement la voie d'Agrippa est assimilée à la départementale D. 158, dont le tracé rectiligne, qui joint le Logis-de-Berre à Saint-Pierre-de-Sénos, paraît pérenniser de façon extraordinaire la voie antique (fig. 6). Aussi, tous les auteurs s'accordent sur ce point. André Piganiol écrit : «La route d'Agrippa est devenue la départementale 158, Claude Boisse note» (Boisse 1968 : 107) : «La Berre franchie (sur un pont?), la Voie d'Agrippa file droit vers le midi, jusqu'aux abords du hameau de Saint-Pierre-deSénos. Elle sert de support, dans ce parcours, en très grande partie, au C.D. 158...», François Salviat renchérit (Salviat 1985 : 278) : «Au Logis de Berre, (...), elle passe sur le tracé de l'actuelle D. 158 ». Cette identification 
s'accorde tout à fait avec le parcours décrit précédemment ; il s'inscrit dans la continuité du tronçon descendant par les «Boisniers » et est validé par les observations faites par Claude Boisse, lors de la fouille de Novem Craris, où un tronçon de voie de $5 \mathrm{~m}$ de large bordé de trottoirs, dans le prolongement de la départementale D.158 et du « grand chemin » a été mis en évidence.

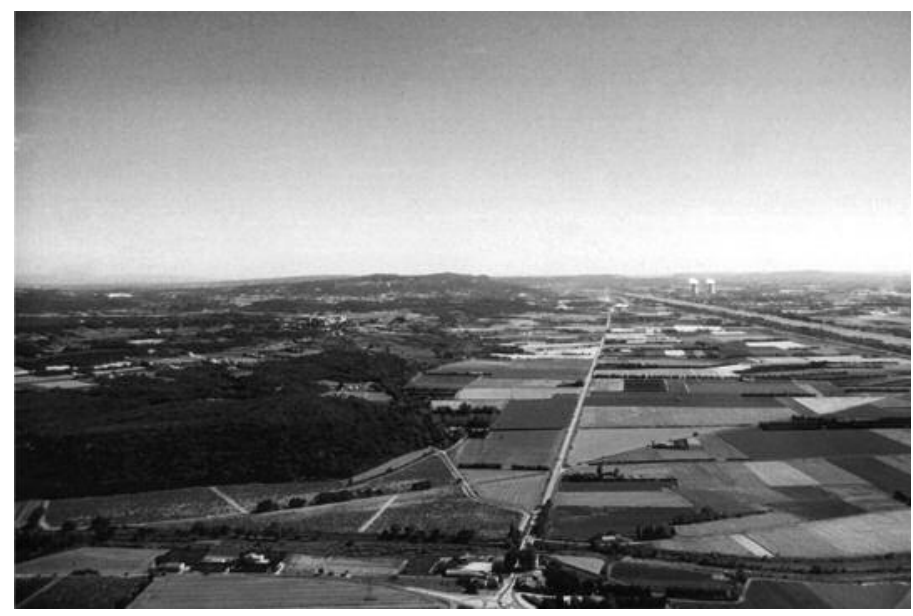

Fig 6 : Photo aérienne de la route départementale I 58 qui fossilise la voie d'Agrippa au sud du Logis de Berre (cl :Th. Odiot, 1994).

Enfin, il s'accorderait avec la découverte, au XVIII ${ }^{e}$ s., du milliaire du Logis de Berre, aujourd'hui à Grignan. Il faut cependant demeurer prudent sur la provenance précise de ce milliaire, souvent attribué de façon définitive au Logis-de-Berre. Florian Vallentin signale en effet que «Paulmier de Latour qui fait connaître la provenance de ce milliaire alors déjà à Grignan, dans une note très courte sur une petite feuille volante semble avoir puisé ce renseignement dans un manuscrit de Peiresc, dans les manuscrits connus de Peiresc, il n'est pas question de ce milliaire ; le milliaire est rapporté sans indication de provenance par Delacroix» (Vallentin 1880 : 389).

Tous ces éléments donnent corps à l'identification de la voie d'Agrippa avec la départementale D. 158. Cependant, lorsque l'on regarde les plaques du cadastre B d'Orange qui représentent la voie à proximité du Logis-de-Berre, on observe des divergences sur sa localisation.

Tout d'abord le tracé de la voie gravée sur les marbres ne coïncide pas avec celui de la D. 158 dans le secteur du Logis de Berre (fig. 7 et 5). En effet, les marbres figurent un tracé plus incliné vers l'ouest. Si la différence d'inclinaison est peu marquée au sud, celle-ci est bien établie au nord, où la voie représentée sur les marbres semble franchir la Berre, non pas au «Pont de Berre », lieu-dit mentionné en 1334 (Bois, vol. III, 29), tout comme la D. 158, mais au niveau du «Pas de Berre » gué situé à l'ouest du Logis de
Berre et attesté en 1562 (ADD 2E 15850 fo77). Que fautil penser de la qualité de représentation des marbres d'Orange ? On sait que les centuries sont représentées sur les marbres sous la forme de rectangles de tailles parfois différentes, alors qu'elles sont matérialisées sur le terrain par des carrés de 20 actus de côté. Il est donc délicat de repositionner exactement sur un fond de carte actuel le tracé donné par les marbres. On est donc en droit de se questionner sur l'exactitude de la représentation de la voie sur les plaques. Cependant il semblerait, d'après les différents fragments représentant la voie que l'on peut confronter à la réalité du terrain ( $c f$. massif d'Uchaux), que sa figuration soit relativement précise.

Dans le cas présent, il faut souligner que le tracé figuré sur les marbres et celui de la départementale D.158 se trouvent, aussi bien au nord qu'au sud, dans les mêmes centuries et passent tous les deux au point de jonction des centuries DD XVII CK II / DD XVII CK I / DD XVIII CK II et DD XVIII CK I. Si les deux linéaires se situent dans les mêmes centuries, la différence de tracé dans la partie nord n'en demeure pas moins flagrante.

La voie gravée sur les marbres ne s'inscrit donc pas dans la continuité du tronçon supposé passer aux «Boisniers », et semble se diriger le long des piedmonts $\mathrm{du}$ «Plateau des Echirouzes ». Il est étonnant de constater que, comme nous l'avons vu, André Piganiol ou François Salviat qui se sont servi des marbres pour établir le tracé de la voie d'Agrippa, n'aient pas souligné ce problème. André Piganiol écrit même : «...ce fragment peut être posé exactement sur la carte moderne. Le graveur antique a tracé la Berre et la route qui la traverse sur un pont, au Logis de Berre » (Piganiol 1962 : 236).

Que faut-il penser de cette voie gravée ? Faut-il considérer qu'elle ne reflète pas la réalité dans ces détails ? Le graveur se contente-t-il de figurer la voie dans la bonne

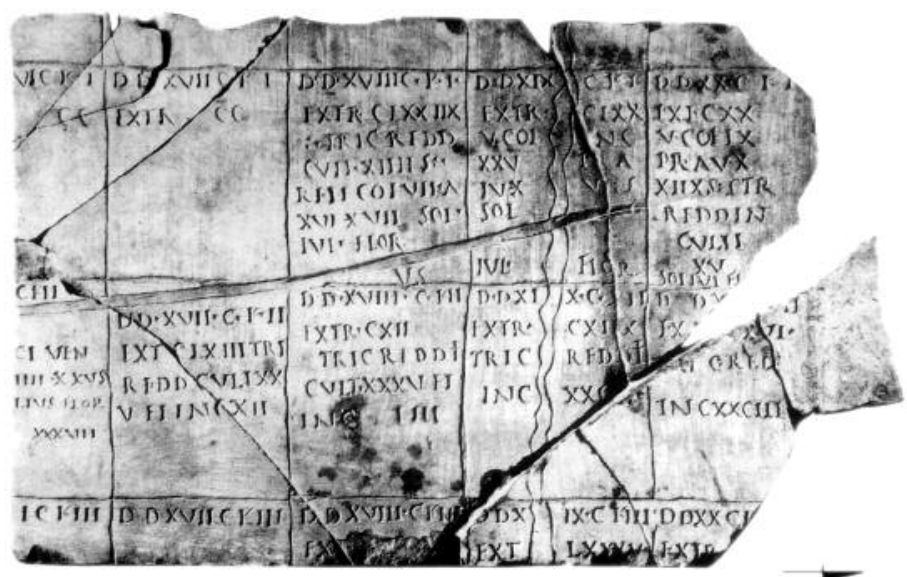

Fig 7 : Photographie des marbres du cadastre B d'Orange dans le secteur du Logis de Berre (cl: Piganiol 1962). 
centurie, le reste n'étant que secondaire ? Cela n'est pas si sûr, il faut, en effet, évoquer au moins un détail souligné par Gérard Chouquer qui accrédite le tracé de cette voie sur les marbres.

La voie d'Agrippa a pu servir de frontière de peuplement aux Tricastins lors de la mise en place de la cadastration B d'Orange. Effectivement, toutes les terres qui leur sont rendues se trouvent à l'est de la voie représentée par les marbres. Gérard Chouquer remarque que dans la centurie DD XVIII CK I, située à cheval sur la voie d'Agrippa, 14 jugères 3/4 sont attribuées aux Tricastins. La surface minimale que l'on devrait trouver à l'est de la route serait au moins égale à celle de ces jugères restituées. Après calculs trigonométriques, la route devrait recouper la ligne de centurie DD XIX à au moins 104,5 m à l'ouest de CK I. Cette distance minimale «correspond » en effet à celle donnée par les marbres (Chouquer 1995).

De plus, au regard des photos aériennes, on distingue la trace d'une limite de parcelle en deçà du «Pas de Berre » qui pourrait correspondre à la voie représentée sur les marbres, à moins qu'il ne s'agisse du prolongement de celle citée en 1562, large de 14 passes (soit environ $9,8 \mathrm{~m}$ ), venant de Donzère. Seul un sondage à cet endroit pourrait nous renseigner à ce sujet.

La voie représentée sur les marbres pose cependant d'autres problèmes. Tout d'abord, ce tracé semble éviter le Logis-de-Berre, pourtant cité comme mutatio par l'Itinéraire de Bordeaux à Jérusalem. Peut-on envisager sérieusement que cet habitat groupé, cité comme relais de la voie d'Agrippa par un itinéraire antique, ne soit pas traversé par cette dernière ? Ou doit-on penser que les marbres gravés en 77 ap. J.-C. sous Vespasien ne présentent pas la même réalité que celle donnée par l'Itinéraire Hiérosolymitain au IV $\mathrm{s}$. La Table de Peutinger, datée du III ${ }^{\mathrm{e}}$ s., ne signale d'ailleurs pas non plus Novem Craris. Le tracé du I ${ }^{\text {er }}$ siècle serait-il différent de celui du $\mathrm{IV}^{\mathrm{e}} \mathrm{s}$ ? Les résultats des fouilles de Claude Boisse, à Novem Craris, tendent à démentir cette hypothèse puisque ce site-carrefour aménagé dès le $\mathrm{IV}^{\mathrm{e}} \mathrm{s}$. av. J.-C est réaménagé sous Auguste (Boisse 1968 : 135).

Enfin, la voie représentée sur les marbres pose une dernière énigme : elle s'interrompt, sans raison apparente, au niveau du Logis de Berre dans la centurie DD XIX CK I (fig. 7). Cet arrêt brutal est expliqué par André Piganiol de la manière suivante : "Le graveur a brusquement arrêté la route, exactement à l'endroit où celle-ci vient buter contre le plateau des Echirouzes, quand le niveau passe de $73 \mathrm{~m}$ à $124 \mathrm{~m}$. (...) Le dessinateur a donc laissé son tracé inachevé à partir du moment où il cessait d'être rectiligne »(Piganiol 1962: 236). Cette explication n'est pas convaincante puisque, nous l'avons vu, le chemin qui emprunte la vallée de pénétration des «Boisniers » est totalement rectiligne. Il faut plutôt penser que l'ascension $\mathrm{du}$ «Plateau des Echirouzes » pouvait s'entreprendre par plusieurs chemins, nous en avons évoqué deux : par les « Boisniers » et par «Javelin ». Il faut aussi rappeler que l'on pouvait gagner Montélimar par la route passant par la villa du Molard, Donzère et Châteauneuf-du-Rhône - le Palais, diverticule certainement important, qui prenait également son origine depuis la voie d'Agrippa au niveau du Pas-de-Berre. Devant la multiplicité des itinéraires qui s'offraient à lui, il est possible que le graveur ait choisi de ne pas figurer la voie impériale.

Cette hypothèse est intéressante car elle donne du poids aux propositions d'itinéraires empruntant la combe de Javelin ou celui passant par Donzère et Châteauneuf du Rhône.

La question du passage de la voie d'Agrippa au niveau du Logis-de-Berre n'est donc pas simple, mais les choses se compliquent encore avec la découverte de la trace fossile d'une voie importante encadrée par de larges fossés, à l'est de la D. 158, qui paraîtrait proche de celle restituée sur les marbres (fig. 5). Cette révélation aérienne a été réalisée par Thierry Odiot ; la trace de cette même voie se dessine aussi très nettement sur une mission I.G.N. de 1960 (FR 213-50, clichés 108 à 113, clichés au 1/5 000). Son tracé est visible depuis la limite sud du parc du château de «Chartroussas », jusqu'au lieu-dit «Fontéron », soit sur près d'un kilomètre (fig. 8). On ne connaît donc pas son tracé à proximité de la Berre ni vers le sud. Son orientation permet de supposer que cette voie se branche sur le chemin qui dessert Saint-Paul-Trois-Châteaux, au lieu de se diriger vers Saint-Pierre-de-Sénos. Le sondage effectué sur cette voie en mars 1994 au sud de Chartroussas atteste de son Antiquité (Jung 1995).

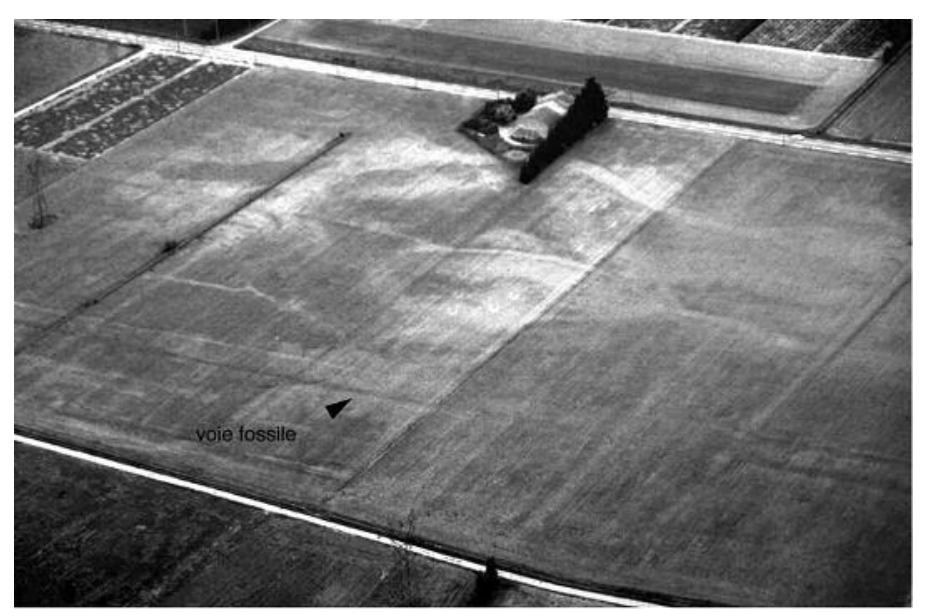

Fig 8 : Photographie aérienne de la voie fossile de Saint-PaulTrois-Châteaux au Logis de Berre au niveau de Chatroussas, (cl :Th. Odiot, 1994). 
Lors de sa découverte, cette voie a été associée à la voie d'Agrippa (Odiot 1994 : 80). Il ne semble cependant pas qu'il faille les rapprocher. En effet, son orientation correspond à celle du chemin qui devait joindre SaintPaul-Trois-Châteaux au Logis de Berre et à la voie d'Agrippa (itinéraire $\mathrm{n}^{\circ} 11$, fig. 13). La liaison entre la voie d'Agrippa et cette route devait s'effectuer au même niveau que le croisement avec le chemin reliant l'oppidum du Moulon à celui de Saint-Etienne-de-Dion (itinéraire $\mathrm{n}^{\circ} 20$, fig. 13 et 15). Cet important carrefour est encore visible dans le paysage actuel et correspond à un croisement de plusieurs chemins. Il est appelé «Croix de la Libération » sur les cartes I.G.N (fig. 5). Enfin, le report du tracé de cette voie dans la grille du cadastre B d'Orange montre qu'elle ne se trouve pas dans les mêmes centuries que le tracé de la voie gravée sur les marbres. Ce dernier élément me semble rédhibitoire.

Il faut donc envisager que deux voies importantes : la voie d'Agrippa, sous l'actuelle D.158, et celle de SaintPaul-trois-Châteaux se côtoyaient sur plus d' 1 km de long avant de rejoindre au sud du Logis-de-Berre, au niveau de la Croix de la Libération. Là, le franchissement de la Berre et le passage vers le bassin valdainais pouvaient être variés : tout droit par Novem Craris et la combe des «Boisniers », soit par le « Pas de Berre » et la Combe de « Javelin » ou par Donzère.

Le tronçon plus au sud ne pose pas de problème. Le tracé de la voie semble correspondre dans les grandes lignes à celui de la D. 158. De plus, les renseignements que donnent les plaques des marbres d'Orange, qui figurent la voie sur les centuries DD XI CK II et DD XII CK II, s'harmonisent avec cette identification. Entre «BollèneEcluse » et Saint-Pierre-de-Sénos, le tracé est aujourd'hui totalement brouillé et en partie détruit par l'urbanisation intensive liée à la construction de la centrale nucléaire, le percement du canal de Donzère-Mondragon et le passage de l'autoroute A.7. Son parcours est cependant repérable sur les cartes d'Etat-Major au 1/50 000 ou sur le Cadastre Napoléonien sous le nom de « chemin ferré ».

\subsection{De Saint-Pierre-de-Senos (Senomago) à Orange (Aurasio)}

À Saint-Pierre-de-Sénos, au niveau de l'église du village, la voie d'Agrippa bifurque en direction du sud-est. Son tracé est maintenant oblitéré à l'intérieur de l'agglomération par les nombreux lotissements construits ces dernières années, mais les cartes plus anciennes retracent l'intégralité de son parcours. À la sortie du village on suit encore son tracé, sous la forme d'un chemin communal appelé « La Levade », du fait de la morphologie de sa chaussée, en ressaut par rapport au niveau du sol naturel. Une coupe a été réalisée à proximité du Lez, par $\mathrm{P}$. Faucher (Rochetin 1883). La voie d'Agrippa présente à cet endroit un profil en surplomb par rapport aux champs qu'elle traverse. Elle est constituée uniquement de couches de graviers et de galets.

Il file ensuite en droite ligne vers le Lez, laissant à l'ouest la ville de Bollène (fig. 9). La mutatio ad Letoce citée par l'Itinéraire Hiérosolymitain est située par Claude Boisse et Guy Barruol au lieu-dit «L'Oratoire » (Boisse 1968 : 155), en bordure de cette route, sur la rive nord du Lez. Pierre Broise émet en 1984 un bémol concernant cette identification. Il n'aurait, en effet, rien relevé d'antique lors de prospections dans le secteur (Broise 1984).

Le problème du franchissement du Lez se pose. Sur la carte d'Etat Major, révisée en 1933, une passerelle est signalée dans le prolongement du chemin décrit plus haut. Aujourd'hui aucun vestige de cet ouvrage n'a été repéré. On ne peut se prononcer sur sa date de mise en service ni sur le type de construction qu'elle a pu pérenniser.

Le chemin n'est plus visible sur la rive sud du Lez, les différentes crues de la rivière et la mise en culture des terres proches du cours d'eau ayant effacé sa trace. On retrouve son souvenir sur la carte d'État Major dans l'orientation d'une ruelle au nord de la départementale D. 94 ainsi que dans celle du chemin qui part en direction des carrières de «Désoulières » au sud de la D. 94, sur la rive gauche du ruisseau des « Noyères ».

Si la voie d'Agrippa paraît avoir été pérennisée de façon évidente dans le tracé de la «Levade» et de son prolongement en deçà du Lez, sur la carte d'État major au $1 / 50000$, il n'en va pas de même pour le tronçon permettant l'ascension du massif d'Uchaux (fig. 9). En effet, on perd sa trace au lieu-dit «Désoulières », où l'exploitation des carrières d'argile à cet endroit, depuis le Moyen Âge, a modifié totalement la topographie antique. On peut néanmoins penser que la chaussée gallo-romaine traversait en droite ligne l'emplacement actuel des carrières en direction du « Devès », premières collines à faire barrage du côté nord. Au-dessus du lieu-dit «Désoulières », on retrouve la trace d'une chapelle en ruine, dédiée à SaintDidier et érigée au $\mathrm{XI}^{\mathrm{e}}$ siècle ainsi qu'un important site du haut Moyen Âge qui s'étend sur près de 5 ha et qui atteste de l'exploitation des carrières d'argile dès l'Antiquité. Il semble fort probable que la voie d'Agrippa passait à cet endroit et a permis plus tard de desservir la chapelle SaintDidier.

Son tracé a dû devenir obsolète avec l'extension des carrières et la création d'une nouvelle route au Moyen Âge. Il s'agit de la départementale D. 12 qui permet actuellement de franchir le massif d'Uchaux et que de nombreux auteurs ont assimilée à la voie d'Agrippa (Boisse 1968: 108). Claude Boisse propose d'autres variantes ne correspondant pas au tracé de la D. 12. La première suivrait la vallée du Lez jusqu'à « Saint-Blaise », puis irait en direction des «Granges Blanches » puis des 
« Granges Rouges » et gravirait les collines suivant le kardo CK XI jusqu'aux «Convenents » avant de rejoindre la D. 12 aux «Farjons ». La seconde hypothèse diverge de la première uniquement dans sa partie basse. Claude Boisse envisage le même tracé que la D. 12 dans la vallée des « Noyères » jusqu'au lieu-dit la « Roquette » avant de regagner l'itinéraire décrit plus haut à la hauteur des "Granges Blanches » en passant à proximité de l'église de Saint-Pierre-de-Derboux. Ces deux itinéraires nous semblent intéressants à envisager, il est certain que le tronçon entre les «Granges Rouges » et les «Convenents » étaient en service à l'époque romaine. Il semble qu'il faille les envisager plutôt comme des itinéraires subsidiaires, mais pas comme la voie d'Agrippa. Nous verrons d'ailleurs plus loin qu'ils ne coïncident pas avec la représentation de la voie sur les marbres. De plus, ils paraissent plutôt en lien, dans leur partie basse, avec des sites médiévaux qu'avec des sites antiques.

Si l'on reprend le tracé de la voie qui a notre préférence, le passage du « Devès » se faisait à la hauteur d'une gorge, où l'on observe encore actuellement un chemin. Au sud de cette gorge, la voie devait continuer au sud-est et passer au niveau de la pointe que fait la limite de commune de Derboux. Là, un chemin, encore visible sur la carte au 1/20 000 levée en 1951, et dans la continuité du tracé décrit précédemment, se dirige à l'est de «Gaucheran ».

On arrive alors dans le secteur des étangs des massifs d'Uchaux. Les sondages réalisés par Xavier Tschanz à proximité des «Farjons » ont permis de saisir les dynamiques morphosédimentaires de ce secteur (Tschanz 1995). Les zones humides semblent asséchées à l'époque romaine, grâce à un effort de drainage, et ne posaient donc pas de problème pour le passage d'une voie. Par contre, cette zone semble redevenir très humide au Moyen Âge ce qui peut expliquer le tracé de la voie médiévale par les coteaux et la disparition des vestiges du cheminement antique. Le tracé de la voie d'Agrippa découle donc, dans cette partie-là, de la juxtaposition de petits tronçons de chemins, encore en activité, qui se trouvent dans l'alignement les uns des autres dans la continuité du tracé précédemment exposé. On retrouve un de ces tronçons de chemin au sud du lieu-dit la «Fontaine» qui traverse la «Serre de Planousset», puis un sentier dans le bois de «Pétardier » qui se dirige vers le Château de Massillan, riche en vestiges antiques (Boisse 1968: 112 et 217) et vers « Hauteville », important hameau dès le haut Moyen Âge.

Au sud de «Hauteville », la voie d'Agrippa est représentée sur les marbres du cadastre B d'Orange dans les centuries SD X CK X et SD XI CK X. La voie gravée est représentée pratiquement au milieu de ces centuries, et son orientation est nord-ouest/sud-est. Si on la reporte sur un fond de carte actuel, elle arriverait, au nord, au niveau de la patte d'oie sur la rive est du ruisseau du « Rossignol » et se prolongerait vers le sud en direction de la colline de la « Gardette ».

La voie dessinée sur les marbres d'Orange est dans l'alignement de l'itinéraire proposé plus haut que l'on perd au niveau de la traversée du ruisseau du « Rossignol » et de l'entrée dans « Hauteville», juste au nord-ouest (fig. 9).

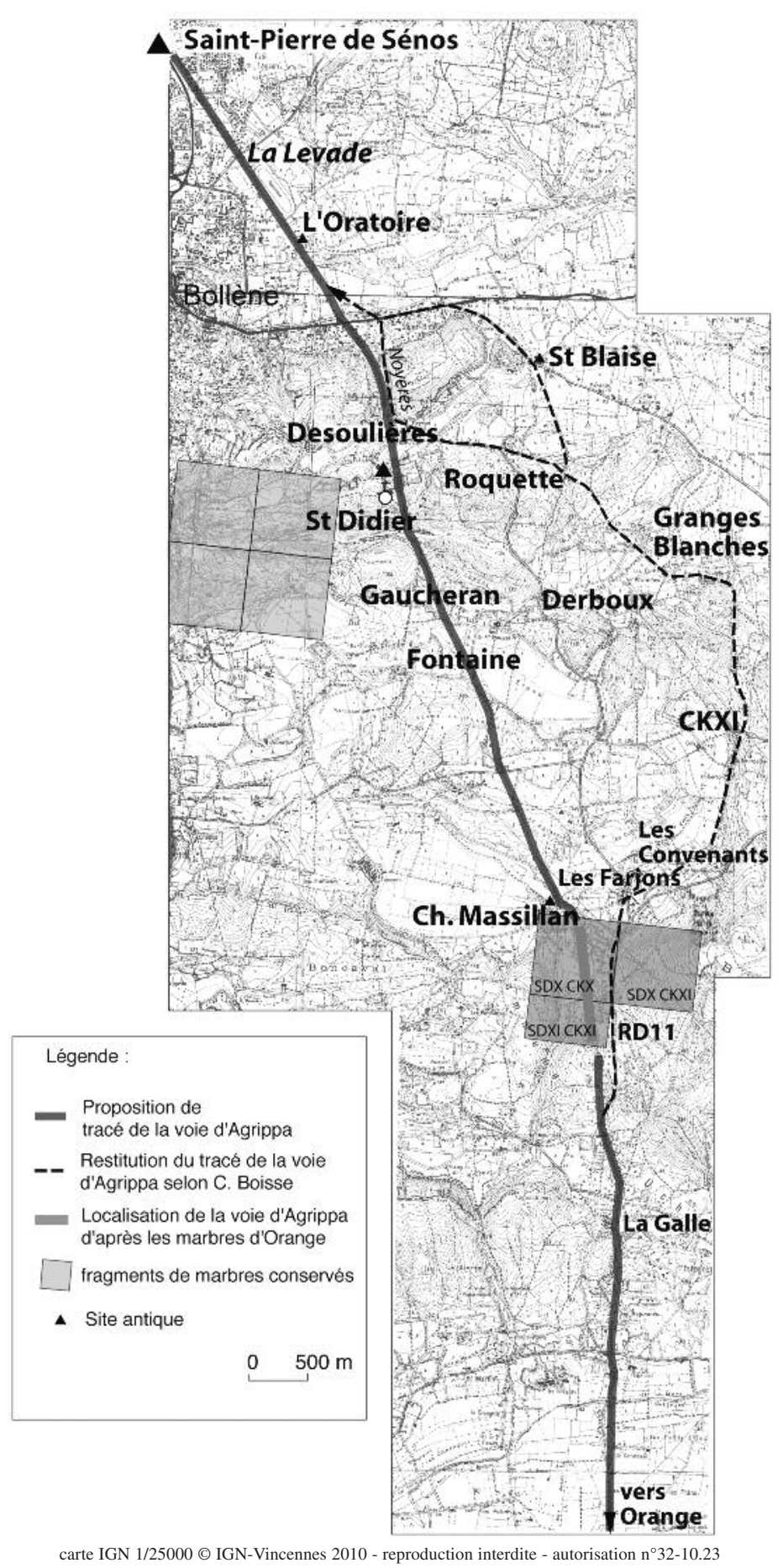

Fig 9 :Tracé de la voie d'Agrippa dans les massifs d'Uchaux (fond IGN I/25 000, série bleue; Jung, 2007). 
Il n'en va pas de même avec la restitution traditionnelle qui assimile la départementale D. 11 (prolongement au sud de la D. 12) à la voie romaine, pour son tronçon rectiligne entre les Farjons et Orange. Effectivement, si celuici se trouve bien à la limite est de la centurie SD X CK X, il n'est pas dans la centurie SD XI CK X mais en SD XI CK XI. André Piganiol relève d'ailleurs ce hiatus qu'il attribue à une erreur du graveur : "La route indiquée est certainement la voie d'Agrippa, dans la section comprise entre Orange et le Lez. mais aujourd'hui cette voie passe en SD X CK XI et non pas en SD X CK X. Il semble donc que, sur la carte antique, le tracé de la route ait été déporté par erreur de 200 mètres environ trop à l'ouest ». (Piganiol $1962:$ 156).

Si l'on considère que le tracé de la voie d'Agrippa sur les marbres d'Orange est conforme à la réalité antique, le graveur ne se serait pas trompé. La départementale D. 11 est orientée sur le cadastre B d'Orange et correspond au dixième kardo à l'est du kardo maximus, entre le hameau des «Farjons », où des vestiges antiques ont été reconnus, et la colline du «Castelas ». On peut donc penser que ce kardo a très vite concurrencé la voie d'Agrippa avant de la supplanter au Moyen Âge.

À partir du «Castelas », le tracé de la D. 12 fait une baïonnette afin de passer dans le hameau de la «Galle». Cette baïonnette se situe au niveau d'un carrefour de chemins, dont l'un peut correspondre à la voie d'Agrippa. Le kardo CK X se «désolidarise » de la départementale D. 12 et s'est pérennisé sous la forme d'un chemin de terre. On peut supposer, d'après les cartes actuelles et la gravure antique, que la départementale D. 12 correspond, à partir de là, au passage de la voie d'Agrippa. Celle-ci part en droite ligne vers Orange.

Le tracé que l'on a exposé jusqu'à présent présente une relative adéquation entre les distances énoncées par les itinéraires et celles relevées sur la carte topographique actuelle. Les seules divergences importantes concernent le secteur que l'on vient de présenter. Les distances reportées sur la Table de Peutinger entre Saint-Pierre-de-Senos (Senomago) et Orange (Arausione), ainsi que celles de l'Itinéraire de Bordeaux à Jérusalem, entre le Lez et Orange, présentent entre 3 et $4 \mathrm{~km}$ de différence avec celles transposées pour l'actuel. Le calcul des distances à partir des cartes IGN est moins fiable dans les zones à fortes dénivellations comme c'est le cas pour le franchissement des massifs d'Uchaux. Le système de projection cartographique a alors tendance à réduire les trajets. Mais la différence de plusieurs kilomètres ne peut pas découler de ce simple problème.

Cet écart d'information pose la question de la validité du tracé entre Saint-Pierre-de-Senos et Orange. Sur les marbres du cadastre B d'Orange, la voie d'Agrippa est représentée dans les massifs d'Uchaux à proximité du hameau de Hauteville, et son tracé est pérennisé de façon exceptionnelle entre Orange et ce secteur par la départementale D. 11 (fig. 9). Le tracé de la voie d'Agrippa semble donc attesté dans les massifs d'Uchaux sans contestation possible au $\mathrm{I}^{\mathrm{er}} \mathrm{s}$. de notre ère. On peut cependant imaginer qu'aux $\mathrm{III}^{\mathrm{e}}$ et $\mathrm{IV}^{\mathrm{e}} \mathrm{s}$. un itinéraire de plaine contournant les massifs d'Uchaux par l'ouest (R.N. 7 et D. 26) a supplanté le tracé par les collines. Les distances relevées sur les cartes sont alors plus compatibles avec celles données par les Itinéraires antiques. Auquel cas, il faudrait identifier la ville de Bollène comme la mutatio ad Letoce et non pas le lieudit l'Oratoire.

\section{Conclusions}

L'analyse critique de l'ensemble des données sur le tracé de la voie d'Agrippa m'a permis de fixer son itinéraire de façon plus fondée que les travaux antérieurs. Ces quelques pages montrent la complexité de l'exercice quand il s'agit de suivre pas à pas le parcours de la voie et de mettre en musique l'ensemble des sources épigraphiques, topographiques, archéologiques et cartographiques.

Même si des doutes et des zones d'ombre persistent ponctuellement, il me semble que l'on a dorénavant une vision plus précise de son tracé entre Montélimar et Orange. Il est certain que les données archéologiques proprement dites, sous forme de sondages de vérification, manquent à cette étude. Ceux-ci permettraient d'attester certaines hypothèses et d'approfondir les questions ayant trait à sa matérialisation.

La construction de la voie paraît très variée, comme tendent à le montrer les quelques données archéologiques que l'on possède. Les rares points d'observation de la voie d'Agrippa ont été effectués dans des contextes particuliers : à l'intérieur d'une agglomération (sondages de Claude Boisse au Logis de Berre) et dans une zone soumise à de fréquentes crues du Lez (sondage de Rochetin à Bollène). Ce qui explique le soin pris pour la construction de la chaussée, par rapport aux observations effectuées sur les hautes terrasses rissiennes qui dominent le Logis de Berre où la matérialisation de la voie est très réduite. La construction de la voie d'Agrippa devait probablement varier considérablement selon le contexte oro-hydrographique et urbanistique. Aussi se présentait-elle soit sous la forme d'une voie bien aménagée (à la proximité des agglomérations ou dans les zones humides), soit sous celle d'une simple piste de terre bordée de fossés (dans la campagne et sur un substrat stable).

Un autre enseignement de cette étude a été de montrer la probable multiplicité des tracés lors des franchissements de reliefs. On le constate pour le massif d'Uchaux, le plateau des Echirouzes et au nord de Montélimar et de Savasse (itinéraire ${ }^{\circ} 2$, fig. 12). Systématiquement on observe que le tracé « officiel» de la voie d'Agrippa est 
doublé par un autre itinéraire qui a pu parfois le supplanter au cours du temps. Ces observations tendent à montrer que le tracé de la voie d'Agrippa a pu varier durant le temps. On note des différences entre les données issues des marbres d'Orange, datés de 77 ap. J.-C. et celles des itinéraires antiques du bas Empire. Entre Orange et Bollène, la voie d'Agrippa passant par les massifs d'Uchaux a sûrement été supplantée par un itinéraire de plaine contournant ces reliefs, qui semble plus en adéquation avec les données des documents routiers antiques.

Outre le travail sur le tracé de la voie d'Agrippa, la mise en évidence d'une série d'itinéraires locaux et régionaux a été rendue possible par une analyse morphologique du réseau routier du XIX $^{\mathrm{e}} \mathrm{s}$. du Tricastin et de l'ensemble de la Valdaine.

\section{LE RÉSEAU DE VOIES SECONDAIRES}

\subsection{Présentation de la méthode régressive}

La méthode d'analyse à partir de laquelle nous avons travaillé pour mettre en évidence un réseau de voies secondaires est celle exposée par Eric Vion (Vion 1989). Celui-ci propose de raisonner sur le réseau routier dans son ensemble, plutôt que sur une compilation forcément lacunaire de tronçons reconnus comme anciens. Il démontre que, tout comme les parcellaires, les réseaux routiers sont dépositaires d'une longue histoire et sont constitués de différentes strates historiques qu'il faut savoir interpréter. Il définit pour commencer trois niveaux de voirie, le réseau local, à l'échelle de la commune, le réseau régional et le réseau supra-régional ; puis il propose de repérer des anomalies à l'intérieur du réseau local. Celles-ci se distinguent à l'intérieur de cet ensemble qui rayonne autour du centre de peuplement communal puisqu'elles ne participent pas à cette logique et semblent s'accorder avec un réseau supra-local qui serait tombé en désuétude. Par ailleurs, l'auteur insiste sur l'intérêt de traiter une vaste portion du territoire qui permet d'embrasser plusieurs agglomérations importantes afin de mettre en évidence le rôle de la dynamique politique et économique des différents centres de peuplement dans la constitution et la destitution des itinéraires.

Son analyse, qu'il a fortement étayée par une étude archivistique poussée, est surtout axée sur le réseau routier du Moyen Âge et son évolution, alors que les périodes plus anciennes ne sont que très peu abordées.

Si l'on reprend rapidement les bases de sa démarche morphologique, il faut, à l'intérieur du cadre communal, où les chemins convergent vers le village et forment ce que l'auteur appelle le réseau local, repérer ceux qui ne s'inscrivent pas dans cette logique et constituent des anomalies qu'il faut relever et analyser.
Eric Vion montre que, dans le canton de Vaud (Suisse) où il a pratiqué son étude, $70 \%$ de ces anomalies sont à mettre en relation avec un réseau régional, déjà en grande partie désuet dans les premières mentions qu'il en a. Elles présentent, pour la plupart, la même orientation que le tracé bien attesté d'un itinéraire et en constituent un doublet. Il montre que plus de $5 \%$ de ces anomalies peuvent relever de réseaux parcellaires antiques, interprétés comme des centuriations.

La méthode du tri morphologique des réseaux d'Eric Vion fait émerger un certain nombre de tronçons de voies qui ont une signification certaine dans la trame routière antique. Elle présente cependant certaines limites en s'appuyant sur une vision de la dynamique et de la structuration du peuplement un peu dépassée aujourd'hui. Eric Vion part du postulat d'après lequel la date de création des habitats groupés et celle de la mise en place du réseau routier local ne serait pas antérieur au haut Moyen Âge $\left(\mathrm{IX}^{\mathrm{e}}-\mathrm{X}^{\mathrm{e}} \mathrm{s}\right.$.), lorsque l'on passe d'un habitat dispersé à un habitat groupé. S'il est vrai que l'Antiquité présente une occupation du territoire plus essaimée qu'au Moyen Âge, il ne faut cependant pas minimiser le rôle important des agglomérations « secondaires » antiques, relais indispensables dans l'économie rurale entre la villa et la ville.

Les résultats du programme Archaeomedes ont bien montré la rétractation, dès le $\mathrm{III}^{\mathrm{e}} \mathrm{s}$. de notre ère, de l'habitat dispersé en Tricastin et Valdaine et l'émergence de pôles importants parfois constitués par l'agglomération de plusieurs sites (Archaeomedes 1998 ; Van der Leeuw, Favory et Fiches dir. 2003). Certains de ces pôles coïncident avec les centres de peuplement communaux actuels et devaient être, dès l'Antiquité, au coeur d'un réseau routier local. Aussi, est-il parfois très délicat de distinguer le réseau viaire local antique de celui des périodes plus récentes et par conséquent de déterminer quelles en sont les anomalies.

L'analyse régressive du réseau routier telle que la propose Eric Vion peut donc présenter des limites certaines, si elle s'appuie uniquement sur les schémas traditionnels concernant la dynamique et la structuration de l'habitat, qui sont désormais discutés. J'ai donc essayé de tenir compte de ces habitats groupés anciens dans l'étude du réseau antique, même s'ils demeurent encore dans une large mesure méconnus.

Malgré toutes ces mises en garde, les résultats du tri morphologique semblent pertinents dans des régions où la carte archéologique est bien documentée, comme c'est le cas pour le Tricastin et la Valdaine. Il est assurément plus confortable de disposer d'une carte archéologique bien incrémentée pour pouvoir donner corps aux propositions de l'analyse morphologique. S'il parait audacieux de dater un chemin en s'appuyant uniquement sur la datation d'un ou deux sites localisés le long de son tracé, ceci semble plus probant si cette hypothèse s'appuie sur un corpus étoffé de sites le jalonnant. 
Il faut également rappeler que la datation des sites pour la période médiévale est souvent établie exclusivement à partir des mentions que l'on peut en avoir. Cependant, ces datations peuvent parfois être rediscutées puisque les prospections thématiques réalisées par Christine Ronco sur le canton de Grignan ont montré que les prieurés de cette micro-région mentionnés autour du $\mathrm{XII}^{\mathrm{e}} \mathrm{s}$. étaient, en grande majorité, implantés sur ou aux abords de sites fonctionnant dès le bas Empire (Ronco 1997).

En conclusion, même si la carte archéologique présente des lacunes, il est essentiel de s'y reporter pour l'investigation des réseaux routiers anciens. Mais cette relation peut être commutative et l'on peut considérer également le tri morphologique des réseaux routiers comme un guide lors des prospections et un instrument d'élaboration de la carte archéologique.

Il faut enfin souligner que la méthode du tri morphologique est plus efficace dans les zones de plaine, où la topographie ne contraint pas le passage des chemins et offre de multiples possibilités. Dans les zones montagneuses, les agglomérations, comme les voies ont privilégié les couloirs naturels de circulation, et les strates historiques de la constitution des réseaux routiers sont, dans ces contextes là, très difficiles à percevoir.

Même si ce principe de restitution des réseaux routiers anciens peut présenter des limites dans certains cas (zones de reliefs accentués, zones où la carte archéologique est mal documentée ou encore dans le cas où le centre communal est déjà en activité durant l'Antiquité), il n'en demeure pas moins pertinent dans son ensemble. Pris individuellement, certains tronçons ne sont probablement pas « authentiques », et seuls les sondages archéologiques pourraient confirmer les hypothèses, mais cette méthode, comme se plaît à le dire Eric Vion, ne veut pas induire un raisonnement sur une compilation de linéaments reconnus comme anciens, mais sur un réseau de chemins.

\subsection{Les résultats de l'analyse morphologique des réseaux routiers}

Le travail d'analyse a été réalisé à partir des cartes d'État-Major au 1/80 000 de Montélimar et d'Orange, levées en 1867 (fig. 10 et 11). L'intérêt de ces documents est qu'ils livrent le réseau routier antérieur aux aménagements du Rhône (canal de dérivation) et aux restructurations contemporaines de la voirie. En revanche, leur lisibilité est délicate et j'ai eu recours à la carte d'État-Major type 1889 levée en 1933 au 1/50 000 ainsi qu'aux cartes IGN plus récentes pour la lecture de certains secteurs. À partir de ce tissu de chemins XIX ${ }^{\mathrm{e}}$, j'ai identifié tous ceux évitant les centres de peuplement médiévaux (fig. 11). De nombreux linéaments, en discordance avec le réseau local de chemins convergeant vers les villages et les agglomérations, ont été mis en évidence dans le bassin de Montélimar et le Tricastin (Chouquer, Jung 1996 ; Jung et al. 1997). Le premier groupe est composé de bribes de chemins mises en relation qui prennent sens et forment un itinéraire. On peut alors identifier les termes de l'itinéraire, associer à son tracé des sites archéologiques et parfois disposer de sondages confirmant l'ancienneté de l'axe et renseignant sur sa matérialisation. Le deuxième groupe est composé de tronçons de voies qui correspondent au maillage du cadastre B d'Orange. Seul un petit nombre de ces axes présentant un intérêt important dans les communications locales sont présentés ici. Les chemins cadastraux repérés sur de petites distances ont été écartés de cette présentation. Le dernier groupe de linéaments qui ressort de l'analyse morphologique correspond à des bribes de chemins dont on n'arrive pas à donner un véritable sens. Ils ont pu ponctuellement servir de doublon à un autre itinéraire. Ces chemins ne sont pas présentés dans les figures synthétiques (fig. 11).

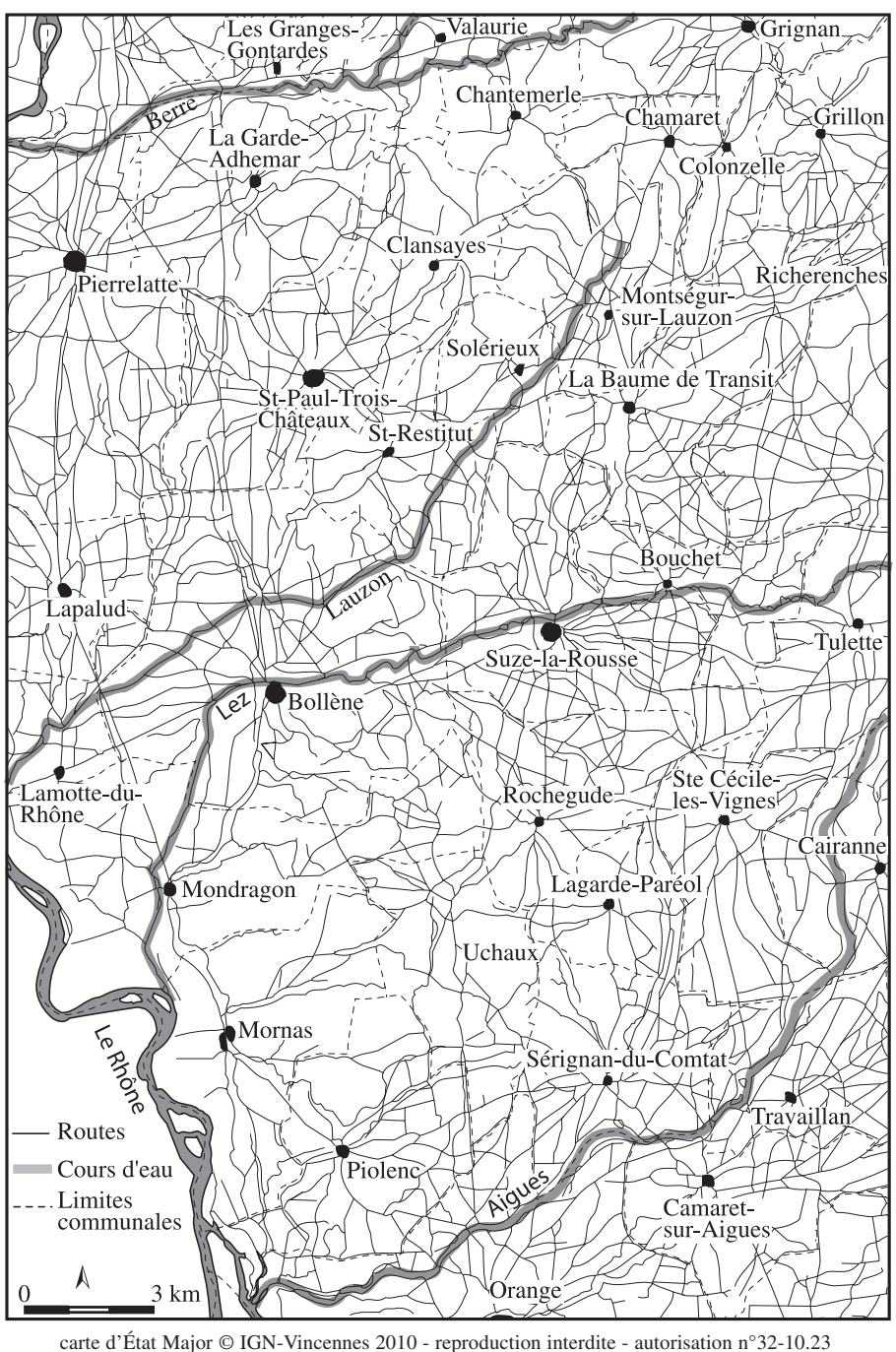

Fig 10: Carte du réseau routier du Tricastin d'après la carte d’État Major de 1867 (Jung, Gonzales Villaescusa ; L. Costa del. 1995). 
La cartographie non exhaustive des 28 itinéraires antiques que je présente ici correspond aux tracés issus de l'analyse morphologique qui, confrontés aux données archéologiques, présentent une cohérence. J'ai ajouté à ce maillage les rares voies connues uniquement par des opérations archéologiques. Il s'agit de chemins repérés en fouille et plus visibles dans le réseau viaire actuel. Enfin, apparaissent également les routes jalonnées de sites antiques, qui relient des agglomérations actuelles d'origine antique et qui ne ressortent pas de fait lors de l'analyse morphologique.

\subsubsection{Les relations nord-sud}

- L'itinéraire $n^{\circ} 1$ n'est pas ressorti de l'analyse morphologique mais correspond à une voie antique qui longe le Rhône sur la rive helvienne (fig. 12 et 13). Même si aucun itinéraire antique ne la mentionne, les nombreux

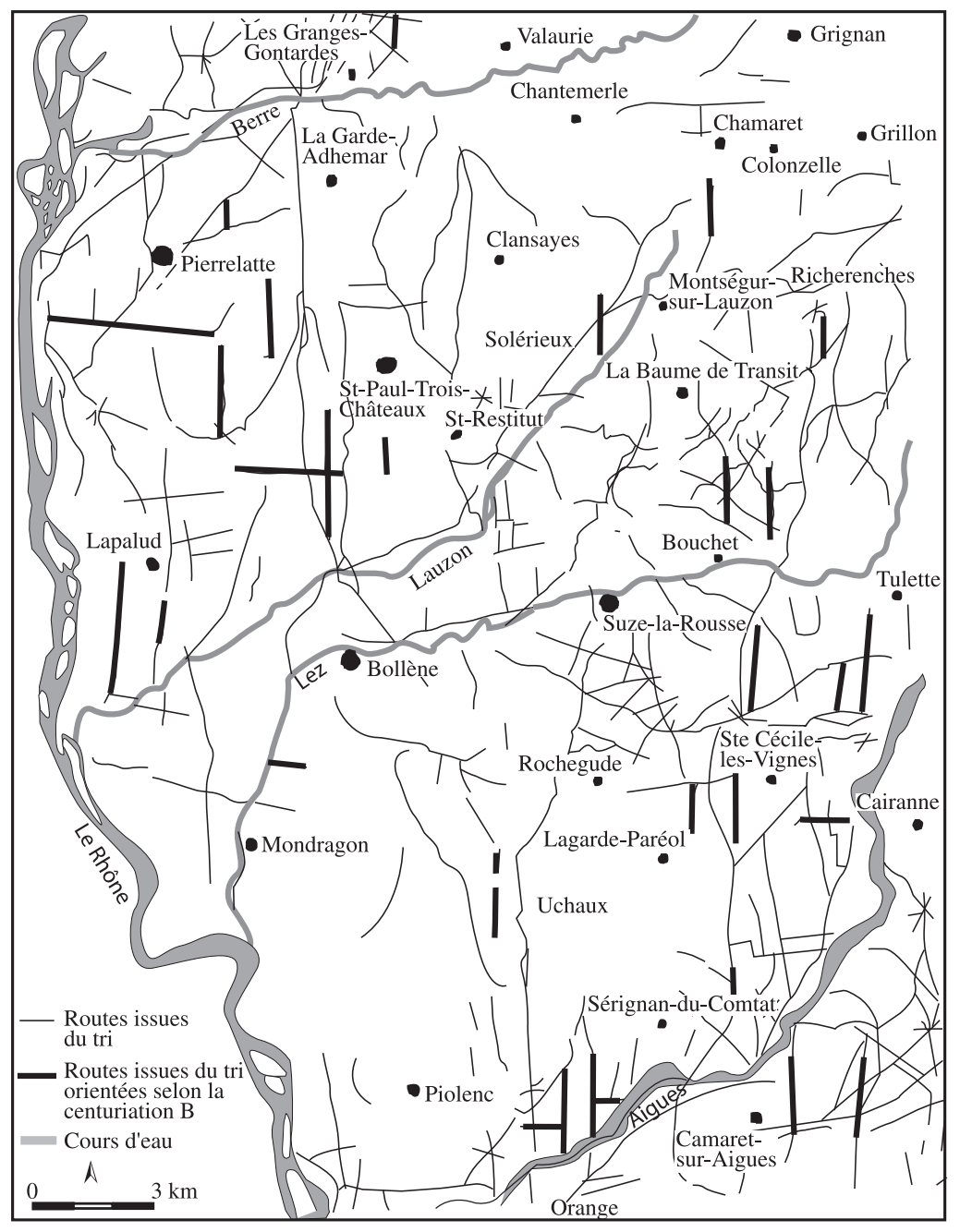

carte d'État Major () IGN-Vincennes 2010 - reproduction interdite - autorisation nº32-10.23

Fig II : Carte des itinéraires antiques en Tricastin et Valdaine repérés par l'analyse morphologique du réseau routier de la carte d'État Major de 1867 (Jung et Gonzales Villaescusa 1995 ; L. Costa del.). milliaires d'Antonin le Pieux (CIL, XVII, 1986) retrouvés à Cruas, Meysse, Rochemaure, le Teil, attestent sont importance et son rang de voie publique. Son tracé correspond dans ses grandes lignes à celui de la RN.86. jusqu'au Teil avant de rejoindre Alba par la vallée du Frayol (Napoli et Rebuffat 1992). Elle se poursuivait depuis le chef-lieu de cité des Helviens en direction de Nîmes, par Barjac et Uzès. L'itinéraire sur la rive ardéchoise devait se poursuivre au sud du Teil et desservir Bourg-SaintAndéol. Cet itinéraire est présenté ici uniquement dans ses grandes lignes, puisqu'il sort de notre aire d'étude mais doit être considéré comme une des voies importantes de circulation de la vallée du Rhône.

- L'itinéraire $\mathrm{n}^{\circ} 2$ constitue un probable diverticule à la voie d'Agrippa, au nord de Montélimar (fig. 12). L'analyse morphologique fait ressortir un faisceau de chemins ruraux de direction sud-ouest / nord-est qui évite la vallée du Rhône et contourne la colline de Savasse par l'est. Ces chemins gravissent les hautes terrasses du Rhône (plateau de Narbonne) qu'ils traversent en diagonale en direction de la vallée sise entre le massif de la «Montagne» et la colline de « Givaude ». Au pied du village de Savasse, des sites antiques, dont un probable sanctuaire, ont été mis en évidence lors de prospections réalisées par le Club Archéologique de Montélimar ( $c f$. itinéraire 18).

- L'itinéraire $n^{\circ} 3$ est déduit par une série de sites importants et constitue un diverticule de la voie d'Agrippa, au sud de Montélimar (fig. 12 et 13). Au lieu-dit « la Fourche », dans les faubourgs de la ville, l'itinéraire se sépare de la voie d'Agrippa et se dirige en direction des collines dominant Châteauneuf-duRhône. Il est pérennisé par la départementale D.73 qui dessert le site du « Palais », sur la commune de Châteauneuf-du-Rhône où des thermes monumentaux, des bâtiments et une nécropole datés du bas Empire ont été mis au jour. Ils pourraient être associés à une agglomération secondaire antique (Jung 1996). On le suit dans les collines entre Chateauneufdu-Rhône et Donzère, où se trouvent les sites proto-médiévaux de «Saint-Saturnin » et «Château Porcher » (Ode 1995 et 1996). Il redescend sur Donzère, agglomération antique reconnue lors des sondages archéologiques réalisés par Thierry Odiot (Odiot 1985 ; Odiot 1994). Après Donzère, le chemin rejoignait la voie d'Agrippa au niveau de la mutatio de Novem Craris (Logis-de-Berre) 
en empruntant soit un chemin en pieds de versant du plateau des Echirouzes, soit en passant à proximité de la villa du Molard, sur la commune de Donzère, où Thierry Odiot a montré les relations existant entre la voie antique et l'établissement viticole (Odiot 1996).

- L'itinéraire $n^{\circ} 4$ est constitué par une série de tronçons de chemins issus de l'analyse morphologique. Ceux-ci dessinent une liaison entre le bassin de Valréas et celui de la Valdaine à travers les massifs calcaires (fig. 12 et 13). $\mathrm{Au}$ nord de Grignan, il correspond à la départementale D. 4 qui gravit les collines séparant les deux bassins. Il passe par le hameau du «Fraysse » et du «Colombier », dans la haute vallée de la Citelle. Il recoupe le chemin Gontardin au niveau du prieuré de Saint-Andéol, sur la commune de la Bâtie-Rolland, installé sur un important site antique. Il prend ensuite la direction du Roubion où il croise l'itinéraire $n^{\circ} 27$, à proximité d'une concentration de sites repérée autour de "Grange Vieille », sur la commune de Sauzet. Son tracé se perd au niveau du franchissement du Roubion, où il converge avec le tracé ${ }^{\circ} 14$ en direction de la vallée du Rhône.

- L'itinéraire $n^{\circ} 5$ ressort avec force de l'analyse morphologique. Ce cheminement traverse en droite ligne le nord du bassin valdainais (fig. 12). Il correspond au tracé des départementales D. 310 et D. 57 a et d'un chemin rural qui gravit les collines de Marsanne en direction soit de Mirmande et de la vallée du Rhône, soit de Grâne et de la vallée de la Drôme. On ne connaît pas de site archéologique le long de cet axe, si ce n'est celui de Queyras, sur la commune de Marsanne, où un fossé de drainage à livré un abondant matériel archéologique de $\mathrm{I}^{\mathrm{er}} \mathrm{s}$. qui indique la proximité d'un site contemporain. Il faut noter que le tracé de la départementale D. 310 suit sur $4 \mathrm{~km}$ environ l'axe théorique du kardo CK16 du cadastre B de d'Orange.

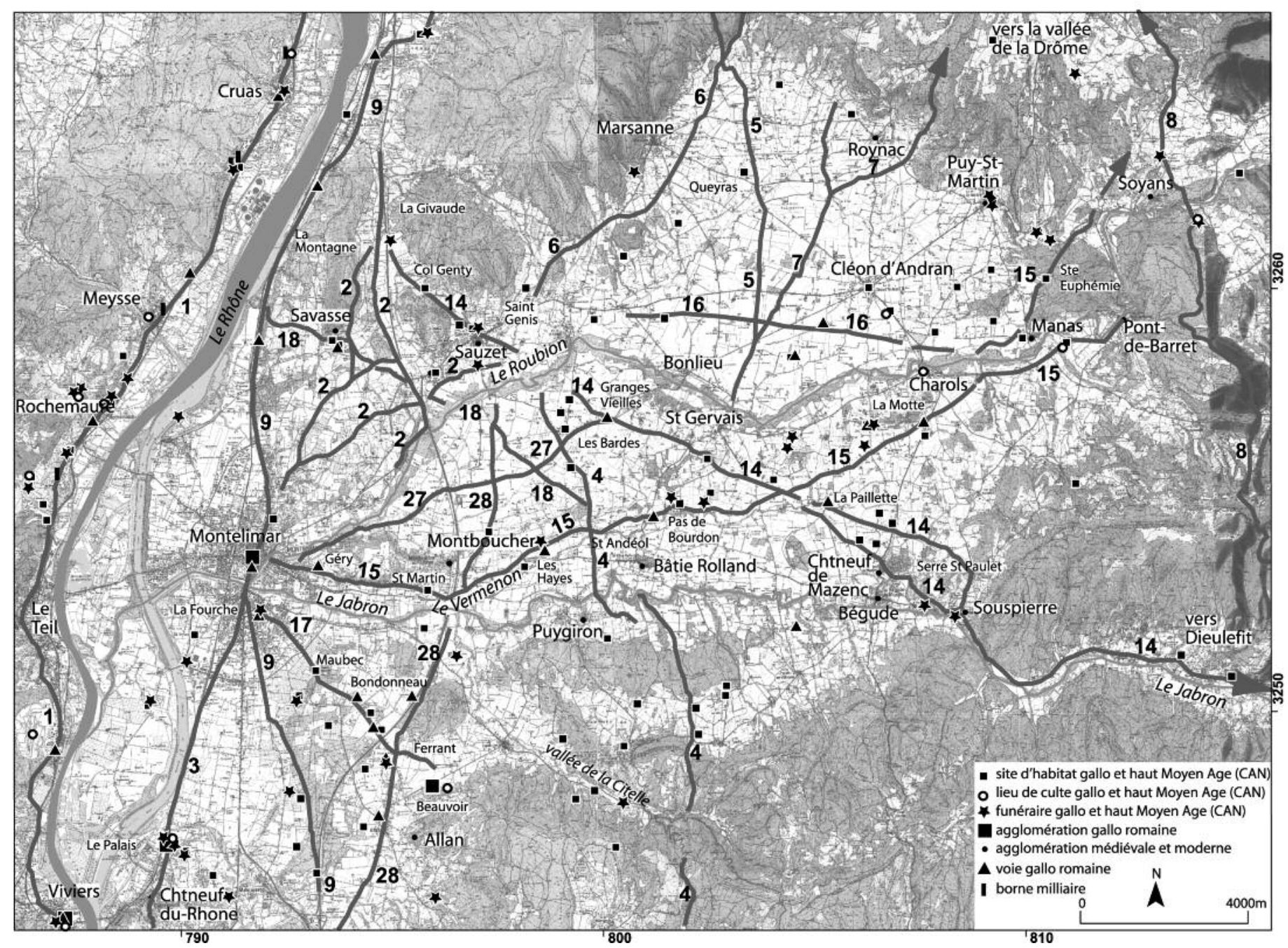

carte IGN 1/25000 @ IGN-Vincennes 2010 - reproduction interdite - autorisation n ${ }^{\circ} 2-10.23$

Fig 12 : Report des itinéraires présumés antiques sur le fond IGN I/25 000 dans le bassin valdainais et des sites d'habitat et funéraires répertoriés dans la C.A.N. (Jung et Sarazin 2008). 
- L'itinéraire $\mathrm{n}^{\circ} 6$ correspond à la voie empruntant les piémonts des collines de Marsanne (fig. 12). Il s'agit de la D.105 qui passe, sur la commune de Sauzet, à proximité du site de «Saint-Genis », site médiéval qui reprend l'emplacement d'un site antique. Un chemin rural évitant le village de Marsanne constitue le prolongement de cet itinéraire. Le chemin rejoint plus au nord l'itinéraire $\mathrm{n}^{\circ} 5$, décrit précédemment. L'absence de prospection systématique sur la commune de Marsanne ne permet pas de mettre en relation cet itinéraire avec des sites archéologiques.

- L'itinéraire $\mathrm{n}^{\circ} 7$ se détache très fortement du réseau de chemin qui dessert les chefs lieux de communes en traversant de façon singulière le nord du bassin valdainais (fig. 12). Il se rapporte, tout comme l'itinéraire $\mathrm{n}^{\circ} 5$, au tracé de la départementale D. 310, mais s'en détache au bout d' $1 \mathrm{~km}$ où il est pérennisé par des chemins de terre qui servent également de limites communales entre
Marsanne et Cléon-d'Andran. Ce tronçon de structure délimite une orientation parcellaire à $\mathrm{NG} \pm 23^{\circ} \mathrm{E}$ qui est très présente sur toute la commune de Marsanne (fig. 14). Plus au nord, le tracé s'infléchit vers l'est et se dirige vers les collines séparant le bassin valdainais de la vallée de la Drôme. Aucun site n'est connu le long de ce chemin mais deux fossés recoupés dans ce secteur lors des travaux archéologiques du TGV-Méditerranée (Bonlieu sur Roubion, Tranchées 585 et 651) présentant la même orientation que ce chemin fonctionnent probablement dès l'Antiquité (Berger et Jung 1999).

- L'itinéraire $n^{\circ} 8$ correspond au chemin protohistorique repéré par Guy Chapotat (Chapotat 1981) (fig. 12, 13, 15). Même si il est en dehors de la zone d'étude, il n'est pas inutile de le signaler, car il constitue, aux yeux de l'auteur un axe important dans l'économie protohistorique du sud est de la Gaule. Cette voie, à l'écart du fleuve,

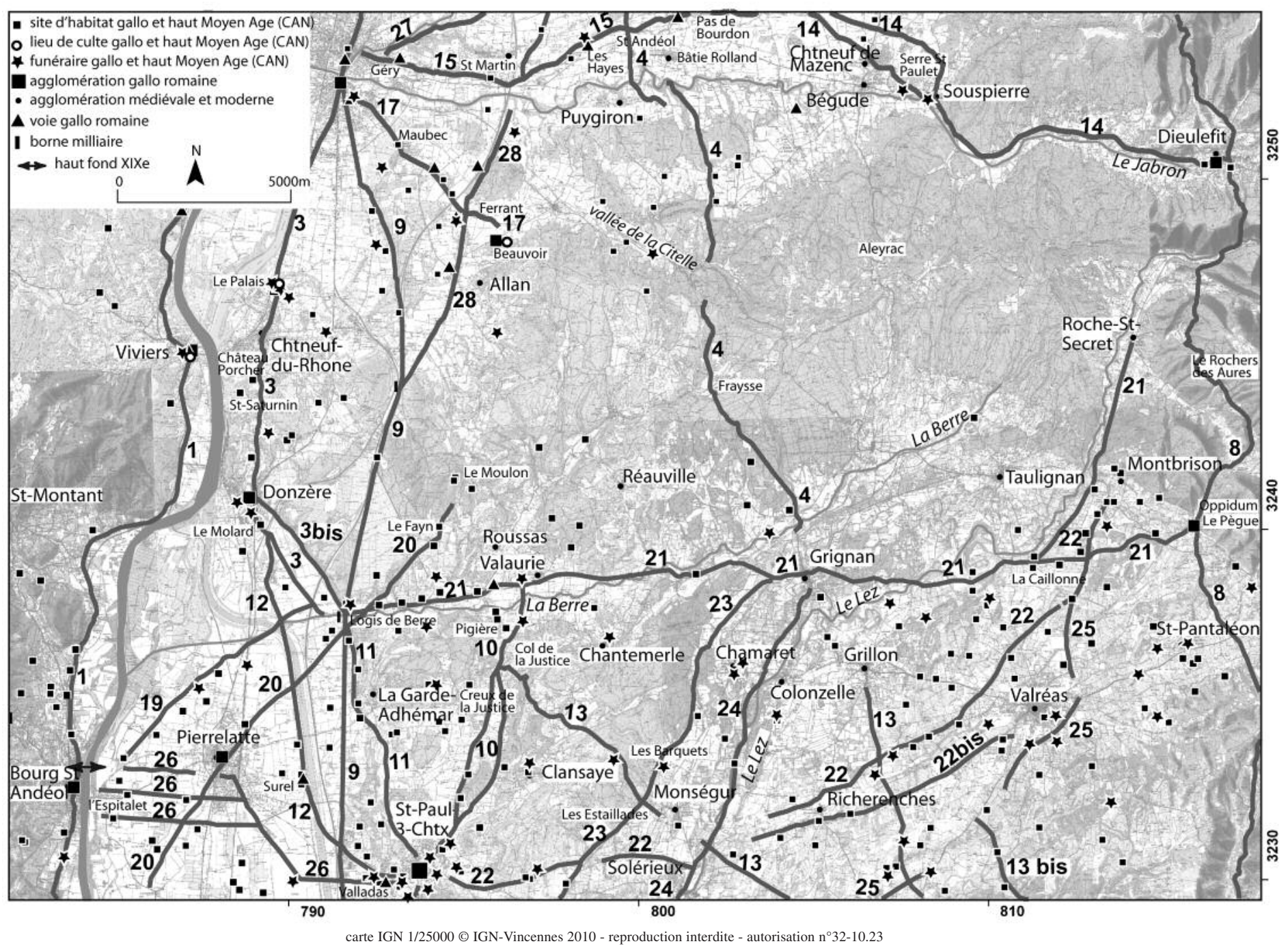

Fig 13 : Report des itinéraires présumés antiques sur le fond IGN I/25 000 du sud du bassin valdainais et du nord du Tricastin et des sites d'habitat et funéraires répertoriés dans la C.A.N. (Jung et Sarazin 2008). 
emprunte l'arrière pays drômois, en passant par Romans, Chabeuil, Crest où elle rejoint la voie des Alpes par le col de Cabre (Valence, Die, Luc-en-Diois, Gap). Cette première partie peu accidentée est encore largement pérennisée par une route départementale. Le profil de la voie entre Crest, Dieulefit, Le Pègue et Vaison-la-Romaine est plus irrégulier avec le passage de cols. Si, dans ses grandes lignes, la voie protohistorique proposée par Guy Chapotat peut être retenue, certains tronçons paraissent peu probables notamment entre le Pègue et Vaison, où l'auteur fait passer la piste par des reliefs très accidentés, et évitant l'agglomération de Nyons. Cet itinéraire est encore très usité au cours du Moyen Âge et jusqu'au XVI ${ }^{\mathrm{e}}$ s. d'après Charles
Estienne (Estienne 1553), dans sa partie nord (depuis Valence jusqu'à la vallée de la Drôme), mais son importance, durant l'Antiquité, est difficilement appréciable. Il faut plus certainement envisager son rôle dans la desserte locale à régionale, avec des tronçons plus actifs que d'autres, plutôt que de voir un itinéraire supra-régional, qui structure les relations au niveau de la Province.

- L'itinéraire $\mathrm{n}^{\circ} 9$ correspond au tracé de la voie d'Agrippa que l'on a décrit en détail dans la première partie de l'article (fig. 12, 13, 15). Entre Montélimar et Orange, elle emprunte les pieds de versants des hautes terrasses rhodaniennes (communes de Montélimar et Châteauneuf-du-Rhône) et des col-

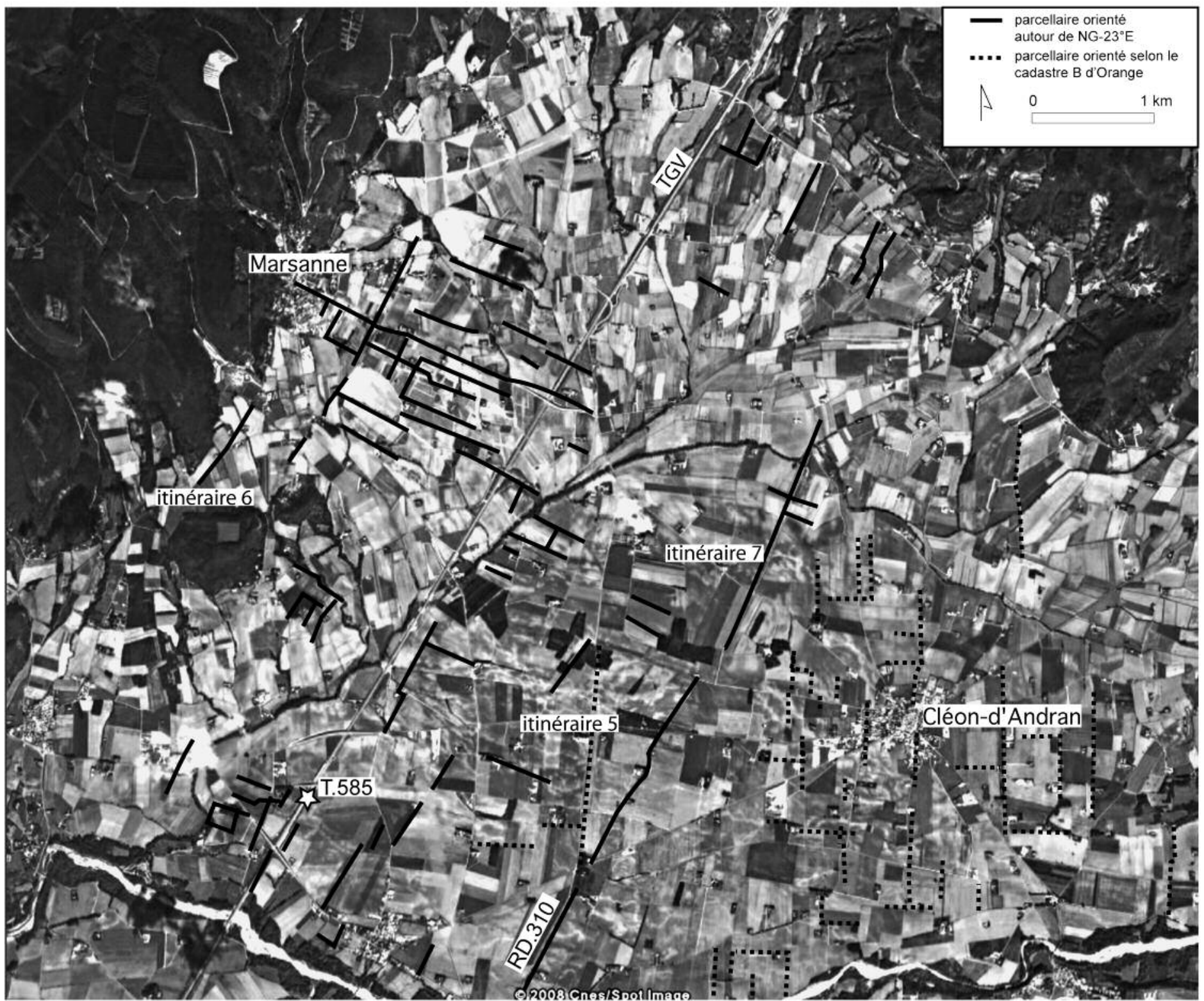

Fig 14 :Vue de détail sur les réseaux parcellaires observés dans le nord du bassin valdainais (fond Spot image / Google Earth 2008) (Jung 2008). 
lines calcaires du Tricastin (communes de la GardeAdhémar, Saint-Paul-Trois-Châteaux et Bollène). Elle gravit le massif d'Uchaux entre Bollène et Orange. Son tracé évite donc, dans cette partie là, les basses plaines alluviales du Rhône et se tient à distance du fleuve, contrairement à son tracé septentrional.

- L'itinéraire $\mathrm{n}^{\circ} 10$ correspond à un chemin qui relie Saint-Paul-Trois-Châteaux, agglomération antique, à la vallée de la Berre, au niveau de la commune de Valaurie. Cette communication est pérennisée par la départementale D. 133 qui emprunte une petite vallée de pénétration en passant en contrebas du village de Clansayes ou par un chemin rural situé plus à l'ouest (fig. 15).

Plusieurs sites antiques jalonnent le chemin rural et une villa ainsi qu'une nécropole ont été repérées au croisement de cet itinéraire avec la voie longeant la Berre (itinéraire $\mathrm{n}^{\circ} 21$ ). Il faut ajouter que le site antique de Pigière (commune de Valaurie), à proximité de ce chemin, perdure durant le Moyen Âge sous la forme d'un prieuré. Par ailleurs, les toponymes « Col de la Justice », «Creux de la Justice » indiquent la présence probable de gibets, et sont autant d'éléments qui attestent une certaine activité de ce chemin durant le Moyen Âge.

- L'itinéraire $\mathrm{n}^{\circ} 11$ correspond à la jonction nord et sud de Saint-Paul-Trois-Châteaux avec la voie d'Agrippa (fig. 15). Il s'agit de chemins qui partent depuis la cité romaine en direction, au nord, du Logis-de-Berre (Novem Craris) et au sud de Saint-Pierre-de-Senos (Senomago). Au sud le chemin qui dessert Saint-Paul-Trois-Châteaux à Saint-Pierre-de-Senos dénommé «ancienne route de Bollène », passe au pied de l'oppidum de Barry.

Le chemin établissant la liaison nord a été photographié par Thierry Odiot lors de prospections aériennes au sud du Logis-de-Berre, on l'a déjà évoqué dans la première partie

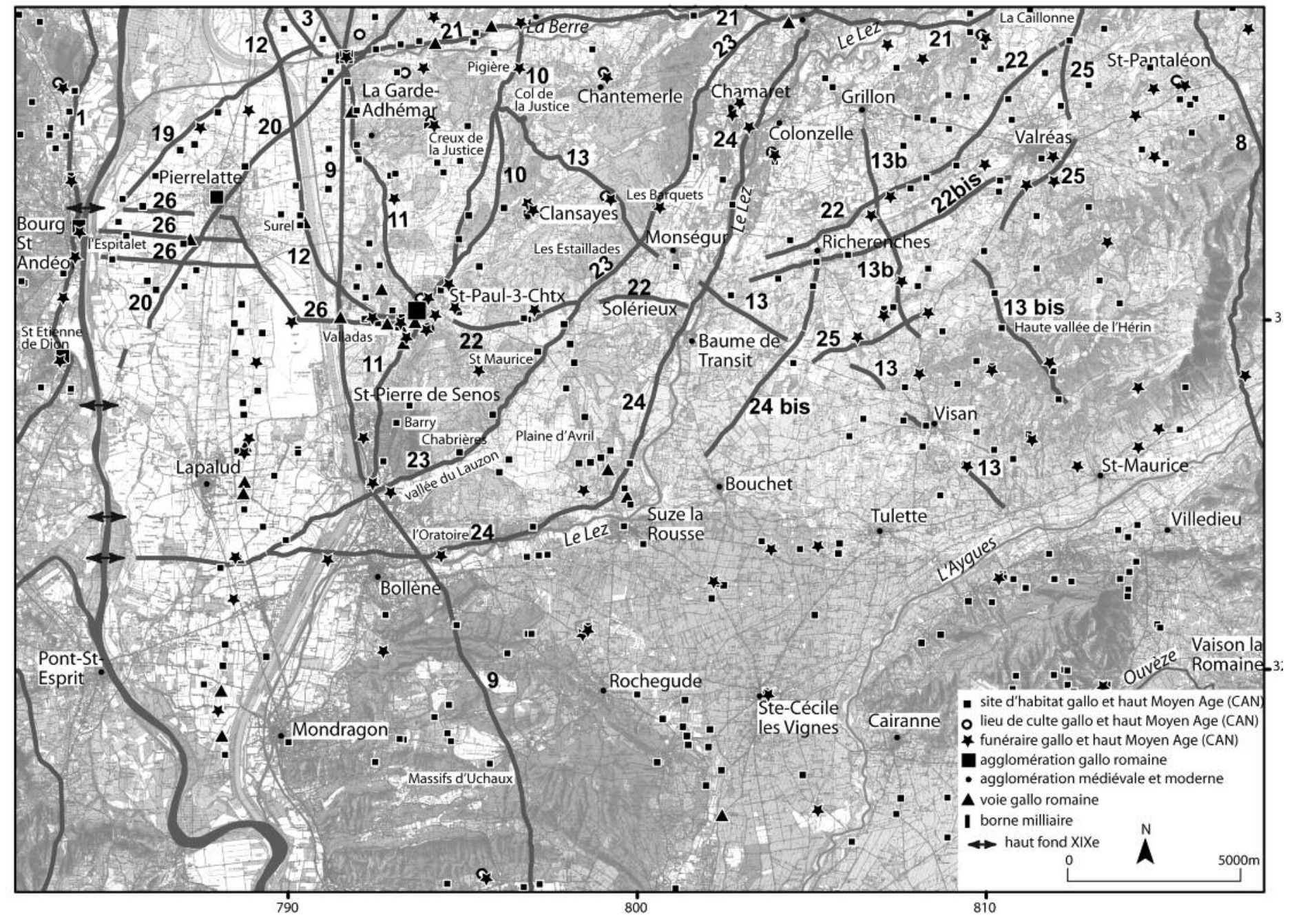

carte IGN $1 / 25000$ ๑ IGN-Vincennes 2010 - reproduction interdite - autorisation n ${ }^{\circ} 32-10.23$

Fig 15 : Report des itinéraires présumés antiques sur le fond IGN I/25 000 du Tricastin et des sites d'habitat et funéraires répertoriés dans la C.A.N. (Jung et Sarazin 2008). 
de cet article. Il l'a confondu avec la voie d'Agrippa (Odiot 1994 : 80), qui passe à quelques dizaines de mètres plus à l'ouest, à proximité de l'actuelle départementale D.158. L'orientation de ce tronçon de voie, légèrement en diagonale par rapport au tracé nord-sud de la voie d'Agrippa, montre que sa direction est dans l'alignement du chemin qui va à Saint-Paul-Trois-Châteaux et ne correspond pas à celle de Saint-Pierre-de-Senos situé sur la voie impériale. Une tranchée a été réalisée sur le tronçon fossile (Jung 1995) (fig. 16). La bande de roulement est très dégradée car très peu enfouie. Seul son hérisson constitué par des galets, des blocs calcaires et des fragments de tegulae est conservé. La voie s'installe sur un niveau sablo-limoneux présentant quelques tessons de céramique antique. La chaussée présente une largeur de $6 \mathrm{~m}$ soit 20 pieds, et est bordée par des fossés. Le fossé oriental présente une ouverture de plus de $3 \mathrm{~m}$ et de nombreuses couches constituent son colmatage avec des curages réguliers. Le fossé ouest montre une série de creusements de plus petite taille qui se succèdent les uns après les autres. Ces fossés successifs sont recouverts et scellés par un alluvionnement dans lequel on retrouve de la céramique antique éparse.

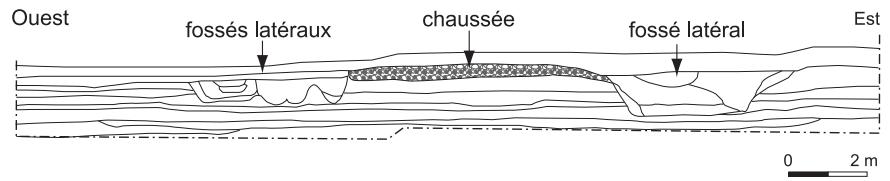

Fig 16: Coupe de la voie de Saint-Paul-Trois-Châteaux au Logis de Berre (itinéraire $\mathrm{II}$ ) réalisée à Chatroussas (la Garde Adhémar, Drôme) (Jung 1998).

- L'itinéraire $\mathrm{n}^{\circ} 12$ reliant probablement Donzère à la voie d'Agrippa en amont de Saint-Pierre-de-Senos n'a pas été repéré lors de l'analyse régressive du réseau routier, car aucun chemin ne pérennise son tracé sur la carte d'État Major du $\mathrm{XIX}^{\mathrm{e}} \mathrm{s}$. Actuellement, une route récente qui borde le canal de dérivation du Rhône reprend plus ou moins son tracé. Cette voie antique n'est pas non plus visible sur les photographies aériennes; les recouvrements modernes liés aux divagations du ruisseau des Echaravelles oblitèrent en effet par endroits la visibilité des vestiges antiques. Ce chemin a en revanche été mis en évidence à plusieurs reprises lors des opérations archéologiques du TGV Méditerranée (fig. 13).

Plusieurs tranchées et un décapage réalisés sur le site de Surel et ses abords ont permis de travailler en coupe et en plan sur ce chemin (Berger et Jung 1999 ; Henry 1997 et 2002 ; Jung 1998). Les observations réalisées sur près de $300 \mathrm{~m}$ renseignent sur la construction de la voie, son orientation et sa datation.
Elle présente une orientation globalement nord-sud, autour de $\mathrm{NL} 1^{\circ}-2^{\circ} \mathrm{O}$. Cette orientation n'est pas éloignée de celle du cadastre B d'Orange (NL $2^{\circ} 30 \mathrm{E}$ ) et la position de la voie est proche de celle du kardo maximus. Il est cependant délicat d'affirmer qu'elle participe de la centuriation. Le calcul de son orientation reste relativement fluctuant selon les tronçons que l'on prend en compte. La variation des orientations s'explique par la matérialisation même de la voie. Celle-ci présente différents états de construction que l'on peut observer en coupe et plus difficilement, lors des décapages. Comme Eric Henry l'avait déjà souligné, les coupes stratigraphiques présentent un profil chaque fois différent des chaussées. La coupe nord relevée sur le chantier de Surel montre clairement deux bandes de roulement juxtaposées (fig. 17). Cette observation n'est pas toujours aisée à faire puisqu'à certains endroits elles ont tendance à se superposer ou à s'imbriquer. Aussi, le profil général de la voie ainsi que sa largeur dans son dernier état sont très variables et il est donc délicat d'en tirer une orientation précise.Les observations faites au nord du site de Surel lors de travaux liés au contre-canal donnent de nouvelles indications sur la construction de la voie. Les coupes analysées mettent en évidence des zones où les galets de la chaussée recouvrent des brandons de bois carbonisés couchés. Les galets et les blocs de calcaire constituant la bande de roulement présentent, dans ces zones là, des traces de rubéfaction et de thermofraction de pierres qui impliquent la simultanéité du brûlis des brandons et la construction de la voie. Ces brandons correspondaient-ils à un marquage préalable du tracé de la voie, que l'on aurait brûlé au fur et à mesure de la construction de la chaussée ? La construction de la voie en graviers et galets, que l'on observe aussi bien sur les zones limoneuses que sur les affleurements de la terrasse, alors que le substrat pourrait se substituer à la bande de roulement, ainsi que la largeur de la bande de roulement (comprise entre 5 et $10 \mathrm{~m}$, selon les endroits pour le dernier état) indique le soin que l'on a porté à la matérialisation de cet axe. Ces remarques sur la structure même de la voie peuvent traduire l'importance de cet itinéraire dans le réseau local. En observant l'orientation générale de la voie et les sites la jalonnant, on peut envisager que cet itinéraire reliait l'agglomération de Donzère, au nord, à la voie d'Agrippa et Saint-Paul-Trois-Châteaux, au sud (fig. 13). La datation de cette voie repose sur celle des bâtiments qui se trouvent à moins de $100 \mathrm{~m}$ de et qui reprennent son orientation (Henry 1997). Leur implantation au début du $\mathrm{I}^{\mathrm{er}} \mathrm{s}$. ap. J.-C. assure l'existence de la voie dès le changement d'ère. L'abandon du site à la fin du $\mathrm{III}^{\mathrm{e}} \mathrm{s}$. concomitant avec celui d'autres sites jalonnant la voie permet de considérer un ralentissement de l'activité de cet axe de circulation à partir de cette période. La présence du paléosol vertique du proto et du haut Moyen Âge qui scelle la structure assure son abandon dans le haut Moyen Âge. 
Pierrelatte, Surel, coupe nord

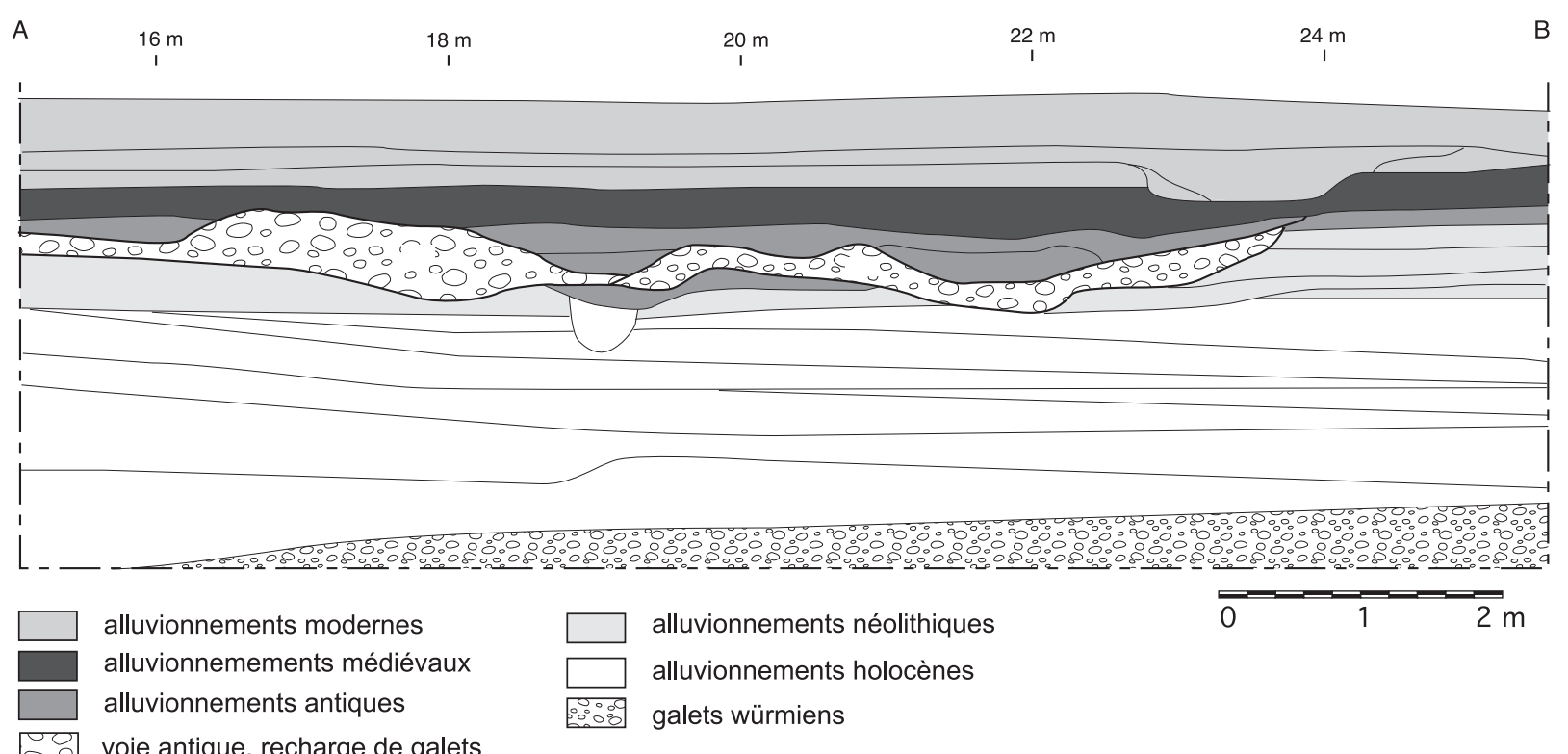

Fig 17: Coupe de la voie de Saint-Paul-Trois-Châteaux Donzère (itinéraire 12) réalisée à Surel (Pierrelatte, Drôme) (Jung 1997).

- L'itinéraire 28 correspond à un chemin reliant la voie d'Agrippa au sortir des collines de Roucoule et Montchamp au bassin valdainais (fig. 12). Il est pérennisé jusqu'au franchissement du Jabron par les départementales D. 126 puis D. 169. Dans l'interfluve Jabron-Roubion il correspond à une série de chemins ruraux. Peu de sites sont associés à cet itinéraire.

- Différents tronçons de voies ressortent de l'analyse morphologique dans le bassin de Valréas. Mis bout à bout, ils permettent d'envisager des relations entre la cité de Vaison et l'arrière-pays tricastin (fig. 15). Un premier itinéraire traverse en diagonale le sud du bassin de Valréas (itinéraire $n^{\circ} 13$ ). On le suit de manière fragmentaire sur l'ensemble de son tracé. Sur la commune de Visan, il correspond à un sentier puis à un chemin rural. Le chemin qui le pérennise plus au nord sert de limite communale entre la Baume-de-Transit et Richerenches. Il traverse les collines de Clansayes avant de rejoindre la voie de SaintPaul-Trois-Châteaux à Valaurie (itinéraire $\mathrm{n}^{\circ} 10$ ) et la vallée de la Berre (itinéraire ${ }^{\circ} 21$ ). L'absence de prospections systématiques sur ces communes de l'arrière pays Tricastin ne permet pas d'associer de nombreux sites antiques à cet itinéraire. On note cependant, sur la commune de Visan, la présence de tombes romaines associées à un établissement qui s'inscrivent le long de cet axe.

Un autre vestige d'itinéraire reliant Vaison au bassin de Valréas peut être reconnu avec le tronçon de voie empruntant la haute vallée de l'Hérin (départementale D. 191, communes de Valréas et Visan). Il est jalonné par de nombreux sites antiques (itinéraire $n^{\circ} 13$ bis).

\subsubsection{Les relations est-ouest}

Certains éléments viaires présentés ici sont associés aux vallées des affluents du Rhône qui contraignent dans une certaine mesure les communications entre la vallée du Rhône et l'arrière-pays et limitent les résultats de l'analyse morphologique. En revanche, dans les bassins alluviaux (Valdaine, Valréas), la mise en évidence des tronçons de voie par la méthode d'Eric Vion acquière une valeur plus importante.

- L'itinéraire $\mathrm{n}^{\circ} 14$, très prégnant dans le réseau de voie étudié, correspond à une voie qui traverse le bassin valdainais en diagonale, reliant la haute vallée du Jabron à la vallée du Rhône à l'écart des chefs lieux de communes (fig. 12). Il est composé de nombreux tronçons de voies encore actifs sur la carte d'État Major. On peut supposer que l'un des confins de cet itinéraire devait être Dieulefit. Le tracé de la voie correspond à l'actuelle D. 540, qui longe le Jabron dans sa vallée encaissée. Au débouché de la vallée, dans le bassin valdainais, l'itinéraire contournait les collines surplombant la Bégude-de-Mazenc, en passant par Souspierre (D. 179), avant de bifurquer en diagonale à la hauteur de la «Blanche» et suivre le cours du Vermenon. Dans ce secteur de la Bégude-de-Mazenc, une concentration de sites antiques jalonne cet itinéraire (Berger 1996). L'itinéraire a pu également contourner les collines du «Serre Saint-Paulet » en passant par les piémonts occidentaux et par Châteauneuf-de-Mazenc en direction du Vermenon. Au sud-ouest de «la Paillette», un sondage réalisé par Jean-François Berger a recoupé une voie antique qui pourrait correspondre à la matérialisation 
de ce chemin. Après la traversée du Vermenon, le tracé de cet itinéraire est pérennisé par la départementale D. 74 puis la D. 12. Cet itinéraire à été recoupé par les sondages systématiques réalisés sur l'opération TGV-Méditerranée dans la tranchée 668 sur la commune de Bonlieu (fig. 18). On remarque trois recharges successives. La première, large de 2,5 m, est constituée de graviers et de galets. La surface de roulement de la deuxième recharge, large de 4,5 m (15 pieds) est constituée de blocs et de galets calcaires, et de rares calcaires. Elle présente quatre ornières espacées de 1,4 et 1,7 m. Des pierres de bordure ont été identifiées le long du côté sud de la voie, le mieux conservé. A la base de cette recharge, des fragments de mortier et une tête de statue en calcaire attribuables aux $\mathrm{II}^{\mathrm{e}}-\mathrm{III}{ }^{\mathrm{e}} \mathrm{s}$. ap. J.-C, ont été recueillis.

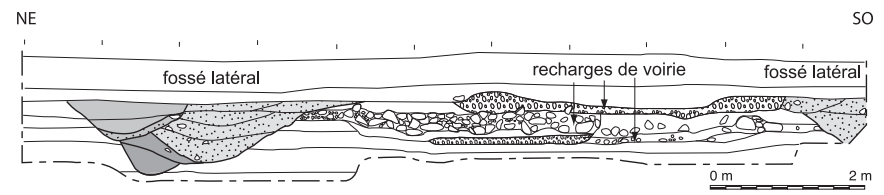

Fig 18 : Coupe de la voie de Dieulefit à la vallée du Rhône (itinéraire 14) réalisée aux Bardes (Bonlieu-sur-Roubion, Drôme) (Berger et Jung 1999).

On observe un fossé de part et d'autre de la voie. La troisième recharge, large de $5 \mathrm{~m}$, se présente sous la forme d'un épandage de gravillons, graviers, galets et éclats de tegulae compactés avec parfois des traces de mortier. Cette recharge est décalée au sud par rapport aux états précédents et le fossé qui peut lui être associé se trouve à $3 \mathrm{~m}$ au nord.

Cette voie est reprise au niveau de «Grange Vieille» par une haie puis un chemin de terre. Sur ce secteur, de nombreuses découvertes effectuées lors des prospections pédestres du Club Archéologique de Montélimar semblent indiquer la présence d'une agglomération secondaire antique, au croisement de cette voie et d'un des kardines du cadastre B d'Orange. On ne connaît pas précisément la position du franchissement du Roubion. On retrouve l'itinéraire sur la commune de Sauzet. Il emprunte le vallon de Laulagnier et franchit le «Col Genty », où une concentration de sites antiques est connue par les prospections du Club Archéologique de Montélimar. Il rejoint ensuite la vallée du Rhône et la voie d'Agrippa.

Le soin apporté à la construction de la voie, ainsi que son entretien matérialisé par la présence de recharges successives, sa largeur, la présence d'ornières que l'on a pu observer dans le sondage de Bonlieu et la pérennité de ce chemin dans le paysage actuel, indiquent l'importance probable qu'a joué cet axe dans la desserte et l'économie locale.

- L'itinéraire $n^{\circ} 15$ correspond au chemin appelé «Gontardin » ou « Costardin », dans les textes médiévaux et modernes (fig. 12). Ce chemin traversait le bassin de la Valdaine depuis Montélimar jusqu'à Manas. Les prospections menées par Michèle Bois dans les collines séparant le bassin de Montélimar de la vallée de la Drôme semblent attester son prolongement en direction de l'agglomération d'Aouste-sur-Sye, mansio le long de la voie des Alpes par le col de Cabre (Bois 1993 : 25).

Le tracé de cet itinéraire correspond, dans un premier temps, au chemin du Géry, qui monte depuis Montélimar au plateau du Géry, constitué par les hautes terrasses du Roubion-Jabron. On le suit sur le flanc sud du plateau jusqu'au prieuré Saint-Martin, sur la commune de Montboucher. Le chemin communal se poursuit, surplombant le Vermenon. Au lieu-dit « les Hayes » une opération archéologique du TGV-Méditerranée, menée par Christine Vermeulen, a permis de recouper le chemin antique et médiéval au nord de la voie actuelle (Vermeulen 2002) (fig. 19). Une préparation du terrain est tout d'abord effectuée. Il s'agit d'un décaissement partiel de la pente sur une
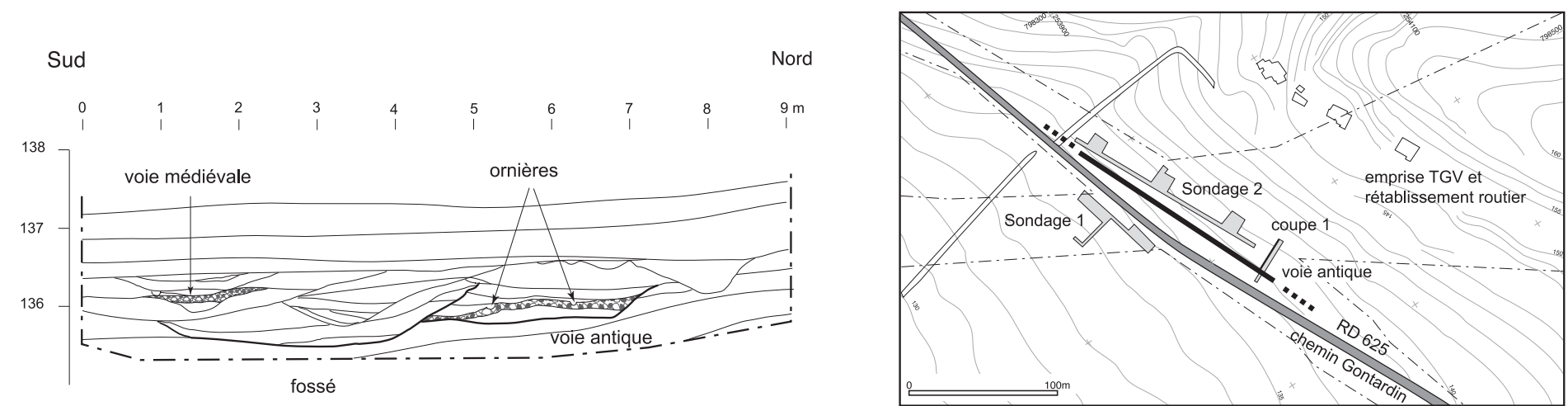

Fig 19: Coupe du chemin Gontardin (itinéraire 15) réalisée aux Hayes (Montboucher-sur-Jabron, Drôme) (Berger et Vermeulen 1999). 
profondeur d'environ $60 \mathrm{~cm}$. La présence de limons sableux dans un contexte de limons argileux sous la chaussée de la voie peut être interprétée comme un apport anthropique en lien avec la construction de la voie. Cette première couche peut servir au drainage sous-jacent de la chaussée. Celle-ci, large de $2 \mathrm{~m}$ est composée de galets et de blocs de grès. Une chaussée médiévale, postérieure au paléosol brun-noir du VII-XII $\mathrm{s}$. a été identifiée. Elle reprend la direction de la voie romaine. Elle est composée de petits galets et graviers épandus sur une dizaine de centimètres d'épaisseur et sur 1,5 m de large. Un fossé la borde au sud. Cette voie est scellée par un colluvionnement mal calé chronologiquement qui atteste d'une déstabilisation des versants. La voie actuelle est légèrement en surplomb par rapport à ces deux axes anciens.

Le chemin se poursuit et est bordé par le prieuré de Saint-Andéol qui fait suite à un site antique (fig. 12). Au lieu-dit le «Pas de Bourdon», un calvaire réemployant une stèle antique (Bois 1993 : 26) marque le carrefour de la voie avec un axe nord-sud reprenant l'orientation du cadastre B d'Orange. L'itinéraire suit l'orientation du ruisseau du Bramefaim et correspond à la départementale D.625. À hauteur de «la Motte», sur la commune de Charols, il est pérennisé par un chemin de terre dont on perd la trace au franchissement du Roubion. À partir de cet endroit, Michèle Bois propose de voir deux itinéraire différents qui relient le bassin Valdainais à la commune de Soyans (Bois 1993 : 26-27). Le premier passerait par la commune de Manas, où un chemin muletier emprunte le flanc occidental de la montagne de Sainte-Euphémie en direction de la commune de Soyans. L'autre itinéraire passerait, non pas par Manas, mais par Pont-de-Barret, où un pont sur le Roubion mentionné dès le $\mathrm{X}^{\mathrm{e}} \mathrm{s}$. et présentant une facture antique est encore visible (Barruol 1969: 320). Le chemin correspond après Pont-de-Barret à l'actuelle départementale D. 179 qui longe le Roubion, avant de rejoindre l'itinéraire décrit plus haut. À partir de la commune de Soyans, la route D. 538 permet de rejoindre Crest. Les vestiges d'un chemin muletier sur quelques centaines de mètres donnent une autre direction vers la montagne de Sainte-Colombe, où des chemins redescendant vers Aouste-sur-Sye sont visibles (Bois 1993 : 26). Il est en effet raisonnable d'imaginer une liaison entre cette agglomération secondaire romaine citée par les itinéraires antiques et le bassin de Montélimar.

- L'itinéraire $\mathrm{n}^{\circ} 16$ ressort avec force de l'analyse morphologique et correspond à un chemin qui sert de limite communale entre Marsanne et Bonlieu-sur-Roubion (fig. 12). Dans le prolongement du chemin précédent, on retrouve des bribes d'autres chemins au sud de Cléon d'Andran, qui se dirigent vers Manas et Pont-de-Barret. Une large voie bordée de deux fossés a été photographiée sur 3 km par Louis Monguilan (Monguilan 1994 : 148) (fig. 20). Elle présente la même direction que cet itinéraire en décalé vers le nord. Cette voie fossile principale est recoupée par trois autres chemins secondaires qui lui sont perpendiculaires. L'importance de ces révélations aériennes pose le problème de l'identification de ce réseau de voies. Leur orientation diverge de quelques degrés de celle du cadastre B d'Orange auquel il paraît délicat de les associer. Louis Monguilan émet l'hypothèse «d'une cadastration rurale » inédite (Monguilan 1994 : 148). On ne peut parler ici de cadastration qui renvoie à une réalité fiscale, ni de centuriation car aucun des éléments mis en évidence ne permet de détecter une rythmicité basée sur l'actus. Il s'agit plutôt d'éléments d'un réseau parcellaire encore mal identifié.

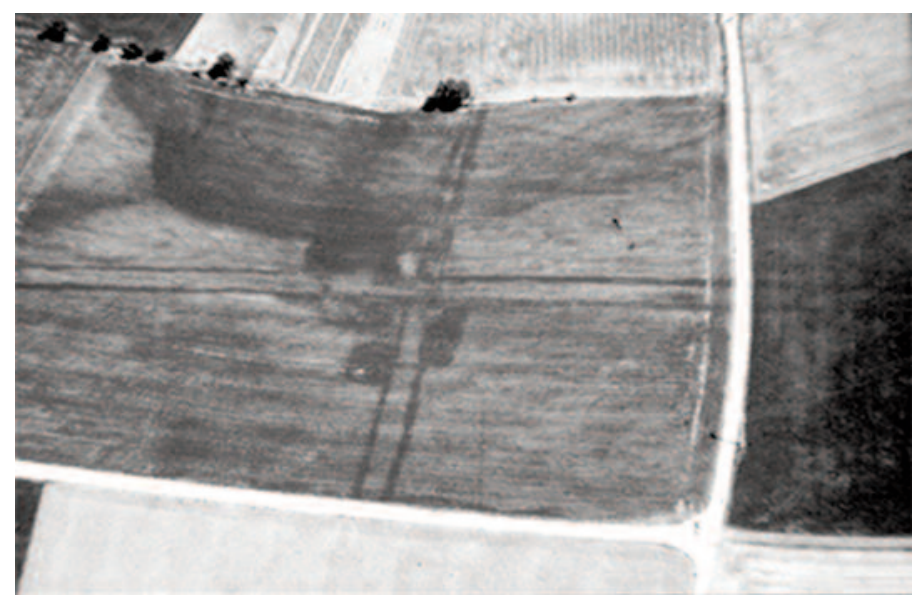

Fig 20: Photographie du croisement de l'itinéraire 16 avec un autre chemin fossile au sud de Cléon d'Andran

(cl. : L. Monguilan).

- L'itinéraire $\mathrm{n}^{\circ} 17$ relie les hautes terrasses d'Allan, voire la haute vallée de la Citelle, au faubourg sud de Montélimar (fig. 12) ; il est également très visible lors de l'analyse. Il est constitué par un tronçon de route départementale D.56, jusqu'à l'abbaye de Maubec. La route se transforme alors en chemin de terre qui monte par un petit talweg sur le plateau de Bondonneau où de nombreux sites antiques sont attestés. Le chemin rejoint, au niveau du lieu-dit «Grange Neuve », un itinéraire nord-sud qui fait la jonction entre la voie d'Agrippa et le Chemin Gontardin (itinéraire 28). Le chemin rural passe au pied de la colline de Montceau, par le hameau de «Ferrent», en bordure d'une zone dépressionnaire humide. Il se dirige alors vers «Beauvoir», où un important site antique est connu. À $300 \mathrm{~m}$ de ce chemin, sur les pieds de versant de la colline de Ramette, un sanctuaire antique fouillé par Valentin du Cheylard en 1880 (Allimant 1994), pouvait être desservi par cet itinéraire. Le chemin arrive aux pieds des collines séparant le bassin de la Valdaine à celui de 
Valréas et devait emprunter la haute vallée de la Citelle, $1 \mathrm{~km}$ plus à l'est, qui constitue une vallée de pénétration naturelle certainement usitée durant l'Antiquité.

- L'itinéraire $\mathrm{n}^{\circ} 18$ relie la voie d'Agrippa au chemin Gontardin, au nord de Montélimar (fig. 12). De plus, ce chemin desservait et reliait probablement entre elles deux concentrations de sites antiques. L'un est situé en contrebas du village médiéval de Savasse. A cet endroit, des vestiges antiques ont été retrouvés sur plusieurs hectares, avec probablement la présence d'un sanctuaire (prospections et renseignements du Club Archéologique de Montélimar). L'autre secteur riche en vestiges antiques se situe autour de « Grange Vieille » sur la commune de Sauzet. De nombreux vestiges antiques ont également été retrouvés sur plusieurs hectares à cet endroit là ( $c f$. itinéraire 14).

- L'itinéraire $\mathrm{n}^{\circ} 19$ correspond à un chemin reliant le Rhône, au niveau de l'agglomération antique de BourgSaint-Andéol, à la mutatio de Novem Craris (Logis-deBerre) sise le long de la voie d'Agrippa et au débouché de la vallée de la Berre (fig. 13 et 15). Cet itinéraire a pu desservir également l'oppidum du Moulon, sur la commune de Roussas, qui surplombe la mutatio. Ce chemin longe le cours de la Berre dans la plaine de Pierrelatte. Quelques sites antiques se développent le long de cet axe pérennisé par différents chemins ruraux.

- L'itinéraire $\mathrm{n}^{\circ} 20$ relie l'oppidum du Moulon, sur la rive drômoise, à celui dominant Saint-Just-d'Ardèche, sur la rive ardèchoise (fig. 13 et 15). Un sentier muletier, un chemin rural et la départementale D. 217 joignent l'oppidum au Logis de Berre, en passant à proximité du site viticole du Fayn. Un gué sur la Berre permettait d'éviter éventuellement la mutatio et de rejoindre la plaine directement. Un chemin rural et la départementale D.118 pérennisent le tracé jusque dans les faubourgs de Pierrelatte. L'extension de la ville brouille la lecture de l'itinéraire à ce niveau. On le retrouve au sud où il longe le cours de la petite Berre, en passant à proximité du site antique de l'Espitalet, sur la commune de Pierrelatte. Il dessert également le site antique de la Dalgonne. À partir de là, son tracé est difficile à discerner, les métamorphoses fluviales du Rhône ayant régulièrement perturbé son lit majeur. Un haut fond sur le Rhône est cartographié au $\mathrm{XIX}^{\mathrm{e}}$ s. au niveau de l'Ile de Saint-Etienne-de-Dion (Poinsart 1992: 92). Ce secteur, situé en amont d'un étranglement naturel du Rhône, appelé le «Banc Rouge» lié à une avancée rocheuse en rive droite, provoque la formation de nombreuses îles dans ce secteur du chenal. Celles-ci pouvaient favoriser la traversée du fleuve, tout du moins en réduire sa largeur. Sur l'autre rive un chemin permet d'accéder à l'oppidum de Saint-Etienne-de-Dion. Les confins de cet itinéraire incitent à penser qu'il a fonctionné dès la Protohistoire et a certainement perduré durant l'Antiquité. Les sites du haut et du bas Empire connus le long de ce chemin permettent en effet de l'envisager.

- L'itinéraire $\mathrm{n}^{\circ} 21$ relie Novem Craris (le Logis de Berre) à la haute vallée du Lez (fig. 13). Cet itinéraire emprunte la vallée de la Berre et est jalonné par de nombreux sites antiques. Il passe aux pieds de Grignan, probable agglomération secondaire antique qui succède à un oppidum protohistorique. L'itinéraire se poursuit plus à l'est par un chemin rural orienté sur le cadastre B d'Orange qui traverse le Lez à gué. Cet axe de circulation se poursuit jusqu'au lieu-dit «la Caillonne» où une concentration de vestiges antiques est visible sur plusieurs hectares (Mège et le Rouzic 1995) et à un carrefour routier. A partir de cette patte d'oie, l'itinéraire continue soit sur le Pègue (Pagus Alteneus), soit vers la haute vallée du Lez, en direction de l'oppidum des Aures, sur la commune de la Roche-Saint-Secret, et la probable agglomération antique de Dieulefit.

- L'itinéraire n ${ }^{\circ} 22$ correspond à une voie reliant SaintPaul-Trois-Châteaux à la haute-vallée du Lez et au Pègue (fig. 13 et 15). La départementale D. 59 pérennise cet itinéraire à la sortie de la ville. Un chemin rural prend rapidement le relais en passant aux pieds des collines surplombant Saint-Paul-Trois-Châteaux, à l'est. On le perd sur la commune de Montségur-sur-Lauzon et dans les alentours du Lez. Son tracé est de nouveau repérable sur la commune de Richerenches sous la forme d'un chemin rural et de la départementale D. 18 qui est jalonnée sur la commune de Valréas par plusieurs sites antiques. La départementale D. 10, dans le prolongement de la D. 18 prend la direction de la commune de Montbrison-sur-Lez et la haute vallée du Lez. Cette voie est également jalonnée par plusieurs sites antiques. La voie recoupe l'itinéraire $\mathrm{n}^{\circ} 21$, précédemment décrit et allant sur l'oppidum du Pègue.

L'itinéraire $\mathrm{n}^{\circ} 22$ bis correspond à un doublon sud de l'itinéraire $\mathrm{n}^{\circ} 22$ (fig. 13 et 15 ). Il se présente sous la forme d'un chemin rural que l'on suit sur plusieurs kilomètres sur les communes de Richerenches, Visan et Valréas. Il sert de limite communale sur une partie de son tronçon entre Visan et Richerenches. Seuls deux sites antiques sont connus en bordure de son tracé, mais aucune prospection systématique n'a été réalisée sur ce secteur.

- L'itinéraire $n^{\circ} 23$ correspond à un grand axe nordest/sud-ouest allant de la rive nord de l'Ardèche à Grignan (fig. 13 et 15). Un chemin dans la plaine du Tricastin, venant de la rive du Rhône au niveau d'un haut fond cartographié au XIX ${ }^{\mathrm{e}} \mathrm{s}$. (Poinsart 1992), traverse la plaine de Pierrelatte d'est en ouest. Il passe par Saint-Pierre-de-Sénos (Senomago), mutatio sur la voie d'Agrippa. L'itinéraire emprunte alors la vallée du Lauzon (départementale D. 160), 
en desservant un très important site antique et protomédiéval au lieu-dit «Chabrières », sur la commune de Bollène. Plus à l'est, il surplombe la plaine d'Avril (commune de Saint-Restitut) où d'autres sites antiques le jalonnent. Il est alors pérennisé par le tracé de la départementale D. 71 puis par un chemin rural au niveau du lieu-dit des « Estaillades », sur la commune de Solérieux. Ce chemin se poursuit jusqu'à Grignan en longeant les pieds de versant du plateau de Rouvergue. Aucun site archéologique n'est connu dans ce secteur, aucune prospection n'ayant été menée à cet endroit. On ne peut donc pas préjuger de l'absence de sites antiques sur ce tronçon de voie.

Cette voie a dû revêtir une certaine importance durant le Moyen Âge au vu des nombreux sites médiévaux qui la jalonnent ou qui se situent non loin (comme le château de Chabrières, sur la commune de Bollène ; le prieuré SaintMaurice, sur la commune de Saint-Restitut ; le village ruiné de Solérieux, la chapelle des Barquets, sur la commune de Montségur-sur-Lauzon, et le village de Chamaret).

- L'itinéraire $\mathrm{n}^{\circ} 24$ relie la rive nord de l'Ardèche à Grignan (fig. 13 et 15 ). Son tracé est le même que celui de l'itinéraire $\mathrm{n}^{\circ} 23$, dans la plaine de Pierrelatte. Les deux itinéraires se séparent sur les communes de Bollène, l'un desservant Saint-Pierre-de-Senos (itinéraire $n^{\circ} 23$ ), l'autre empruntant la vallée du Lez. Cet axe passe par le lieu-dit « l'Oratoire », où certains voient la localisation de la mutatio Ad Letoce citée par les itinéraires antiques (Barruol 1969 : 74 ; Boisse 1968 : 136). La voie longe le cours de Lez, qui présente une direction est-ouest jusqu'à la commune de Suze-la-Rousse. Elle bifurque alors, comme le cours d'eau, en direction du nord où la départementale D. 117 pérennise son tracé. Sur la commune de la Baume-de-Transit, la départementale se transforme en chemin rural, puis en chemin de terre que l'on suit avec plus ou moins de difficulté jusqu'à Grignan.

$\mathrm{Au}$ nord du village de Bouchet, on peut observer un autre itinéraire ( 24 bis) qui ressort fortement du réseau viaire de ce secteur (fig. 15). Il part en diagonale à travers le bassin de Valréas après avoir traversé le Lez. Il s'agit d'un chemin rural qui sert également de limite communale entre les communes de Visan et de Richerenches sur une partie de son tracé. On le perd au sud de Richerenches avant la traversée du ruisseau de la Coronne ? Il semble se brancher sur l'itinéraire $\mathrm{n}^{\circ} 22$ pour se diriger vers le Pègue et la haute vallée du Lez.

- L'itinéraire $n^{\circ} 25$ correspond à une voie traversant en diagonale le sud du bassin de Valréas (fig. 13 et 15). On la suit sur les communes de Bouchet et de Visan. On la perd aux confins des communes de Richerenches, Visan et Valréas, mais elle peut être rattachée au nord-ouest à un autre tronçon d'itinéraire se dirigeant vers la haute vallée du Lez et qui est dans son alignement.
- L'itinéraire $n^{\circ} 26$ correspond à la voie reliant SaintPaul-Trois-Châteaux à Bourg-Saint-Andéol (fig. 13 et 15). Il emprunte une série de decumanus du cadastre B d'Orange. A la sortie de la cité antique, il s'agit du $8^{\mathrm{e}}$ decumanus, le long duquel se développe la nécropole du Valladas fouillée par Valérie Bel. Il emprunte ce decumanus jusqu'à la hauteur du kardo maximus où une voie en diagonale lui permet de rejoindre les $10^{\mathrm{e}}, 11^{\mathrm{e}}$ et $12^{\mathrm{e}}$ decumani jusqu'au Rhône. Ces axes est-ouest structurent une partie des établissements ruraux de la plaine de Pierrelatte. Il s'agit de sites présentant une superficie importante et une longue séquence chronologique.

\section{AnAlyse du RÉSEAU de COMMUnication EN Tricastin ET VALDAINE}

\subsection{Hiérarchie des itinéraires routiers}

Les vingt-huit itinéraires émergeant de l'analyse morphologique permettent d'esquisser certaines des relations qu'entretiennent les pôles de peuplement entre eux et de faire émerger des groupes selon l'échelle des relations mises en évidence. On constate en effet que ces itinéraires ont pu jouer un rôle dans des liaisons interprovinciales, ou le plus souvent régionales, voire locales.

La voie d'Agrippa ( $\left.n^{\circ} 9\right)$, la voie helvienne $\left(n^{\circ} 1\right)$ et la voie des piémonts $\left(\mathrm{n}^{\circ} 8\right)$ correspondent à des axes suprarégionaux dont les termes débordent amplement de notre cadre d'étude. Ces trois itinéraires à grandes distances ont chacun des particularismes très forts. On note cependant qu'ils n'attirent pas ou peu les sites ruraux le long de leur parcours, hormis les établissements de service, comme celui de « Termini » à Malataverne, sur la voie d'Agrippa. En revanche, ces axes mettent en relation les petites agglomérations servant de relais routier ainsi que les cités ou les oppida, pour l'itinéraire de G. Chapotat. La voie helvienne à l'étroit entre le Rhône et les collines ardéchoises est, du fait des contraintes topographiques, jalonnée par plus d'établissements ruraux que les autres voies de ce groupe. La majorité des sites qui lui sont associés relèvent cependant du funéraire, ce qui paraît cohérent le long d'une voie. Ces axes ont donc peu d'influence dans la structuration du peuplement et concernent une économie à longue distance.

La majorité des itinéraires ressortant de l'analyse morphologique correspondent à des relations que l'on peut qualifier de supra-locales à régionales. Elles mettent en relation des agglomérations romaines entre elles (Vaison, Saint-Paul-Trois-Châteaux, Montélimar, Orange, Alba) ou avec des couloirs de circulation importants (vallée de la Drôme, vallée du Rhône). Ces axes sont jalonnés, dans les secteurs où la carte archéologique est renseignée, par des nombreux établissements ruraux, voire de petites agglomérations et des sites funéraires. 
Dans le bassin valdainais, on note essentiellement des itinéraires liant Montélimar ou le couloir rhodanien avec l'arrière-pays. L'itinéraire $\mathrm{n}^{\circ} 14$ mettant en relation la haute vallée du Jabron, avec la vallée du Rhône participe de cet ensemble. Il en va de même pour le chemin Gontardin $\left(\mathrm{n}^{\circ} 15\right)$ reliant Montélimar à la haute vallée du Roubion et la vallée de la Drôme au niveau de l'agglomération romaine d'Aouste-sur-Sye (Augusta), sise sur la voie des Alpes. L'itinéraire $n^{\circ} 4$ mettant en relation le bassin de la Valdaine avec celui de Valréas, voire la vallée de l'Ouvèze, si on le prolonge par l'itinéraire $n^{\circ} 13$, présente un intérêt certain. L'absence de prospection dans les zones montagneuses qui pourraient donner plus de corps à cet itinéraire est dommageable.

Dans le bassin de Valréas, on observe une série de chemins qui semblent converger vers Vaison, indiquant une dynamique entre la cité romaine et ce territoire (itinéraire $\mathrm{n}^{\circ} 13$ et variantes). Jean-Claude Mège a d'ailleurs montré l'influence de Vaison sur le pagus Alteneus, associé au site du Pègue, par la présence dans le bassin de Valréas de marqueurs cultuels caractéristiques de la cité des Voconces (Mège 1986).

Par ailleurs, l'itinéraire $\mathrm{n}^{\circ} 22$ illustre les relations entre Saint-Paul-Trois-Châteaux et le Pègue. Les nombreux sites jalonnant son tracé attestent la dynamique de cet axe.

Les relations entre les deux rives du Rhône se distinguent également. Elles sont mieux renseignées pour le Tricastin, où l'on a pu les associer à des hauts fonds du Rhône, cartographiés sur les documents du $\mathrm{XIX}^{\mathrm{e}} \mathrm{s}$. lors des premiers travaux d'endiguements du fleuve (Poinsart 1992). Ces hauts fonds, qui en période d'étiage sont, en 1876, à moins d' $1 \mathrm{~m}$ de profondeur, posaient des difficultés pour la batellerie. Certains d'entre eux, correspondant à des ressauts calcaires, sont stables (par exemple au niveau de Bourg-Saint-Andéol, itinéraires $n^{\circ} 19$ et $n^{\circ} 26$ ). D'autres, liés à l'accumulation de sédiments, sont plus mouvants, le courant du Rhône pouvant les remobiliser et faire varier leur position. Cependant, les secteurs cartographiés ici sont situés en amont ou en aval de zone d'étranglement du chenal, favorables à la constitution d'îles et de hauts fonds, ce qui implique une certaine stabilité de ces formations. Il est intéressant de voir la corrélation entre les itinéraires issus de l'analyse morphologique et ces écueils sur le Rhône. Les itinéraires n 23 et 24 qui se dirigent vers le Rhône en amont de sa confluence avec l'Ardèche se situent au niveau d'un de ces hauts fonds. Ils présentent un intérêt régional important entre l'arrière-pays Tricastin et la rive helvienne, voire la vallée de l'Ardèche.

L'hypothèse d'au moins trois points de passage entre les deux rives du Rhône sur moins de 10 km de long, entre Bourg-Saint-Andéol et Pont-Saint-Esprit montre, que le Rhône ne constitue pas une limite géographique infran- chissable, mais comme l'évoque Philippe Leveau, il existe « une vie fluviale intense qui ne repose pas sur la seule utilisation du fleuve dans sa dimension longitudinale de voie de communication » mais également sur celle de ses rives illustrée par les bacs, ports et embarcadères qui les jalonnent (Leveau, à paraître).

L'analyse n'a pas été réalisée pour les communes au sud d'une ligne Bollène, Suze-la-Rousse, Tulette, SaintMaurice-sur-Aygues et les relations entre Orange et le bassin de Valréas n'ont pas été perçues. Elles doivent pourtant exister et certains chemins sur la commune de Sainte-Cécile-les-Vignes les pérennisent probablement.

Les dessertes plus locales sont également présentes dans le tissu d'itinéraires issus de l'analyse. Elles correspondent à des chemins de raccordement entre les agglomérations et d'autres itinéraires ou sont au réseau de communication relevant de la centuriation B d'Orange. J'ai écarté ces derniers de la présentation définitive de l'analyse morphologique car ils présentaient en général de petits tronçons difficilement interprétables. Ce réseau est cependant prégnant sur les documents planimétriques et certains de ces axes ont été retrouvés en fouille lors de l'opération TGV-Méditerranée (Berger Jung 1999 ; Jung 1999). L'itinéraire $n^{\circ} 26$ fait partie de ces chemins cadastraux, mais l'intérêt qu'il revêt dans la structuration locale est incontournable. Cet itinéraire fait apparaître avec force les relations entre Bourg-Saint-Andéol, Pierrelatte et Saint-Paul-Trois-Châteaux. Il est jalonné par les sites importants de la plaine du Tricastin et met en relation les pôles de peuplement de part et d'autre du Rhône.

\section{2. Émergence de pôles d'attraction du réseau routier}

Les résultats présentés ci-dessus mettent en évidence les forts points d'attraction du réseau routier (fig. 12, 13 et 15). Il s'agit, pour le Tricastin, de la haute vallée du Lez au niveau de la commune de Montbrison, passage obligé pour rejoindre l'oppidum des Aures, sur la commune de la Roche-Saint-Secret, et Dieulefit, probable agglomération secondaire antique. Le pont en ruine sur le Lez, au niveau de Montbrison, correspond certainement à un aménagement antique. Cette infrastructure, peu commune dans cette région, montre l'importance de ce point de franchissement. Le faisceau d'itinéraires convergeant vers ce point témoigne également du rôle économique qu'a joué la haute vallée du Lez. Cette vallée qui mène à Dieulefit permet ensuite, en passant par le col de la Chaudière, de regagner la vallée de la Drôme, à la hauteur de Saillans (mansio Darentiaca sur la voie des Alpes), non loin de la cité romaine de Die.

Le village du Pègue semble aussi attirer à lui les chemins anciens. Le puissant oppidum de l'âge du Fer dominant le village actuel du Pègue, est peu à peu délaissé au 
cours de l'Antiquité. L'habitat et le centre administratif et religieux paraissent se déplacer vers le village actuel. $\mathrm{La}$ dédicace épigraphique retrouvée à Taulignan concernant un édile du pagus Aletanus atteste l'existence d'une agglomération importante dans le secteur. Le vocable de « Notre-Dame d'Auton », église du Pègue, rappelant le toponyme antique ainsi que les nombreuses découvertes archéologiques effectuées dans le village, forment un faisceau de présomptions pour identifier le Pègue comme le chef-lieu du pagus. On comprend mieux, alors, son rôle dans la constitution du réseau routier.

Le statut de Grignan est plus délicat à définir. Quelques découvertes fortuites attestent la présence d'un habitat antique que l'on ne peut définir par ces seuls vestiges sporadiques. Cette agglomération semble cependant jouer très tôt un rôle important dans la constitution des itinéraires anciens de l'arrière-pays tricastin puisqu'un certain nombre d'entre eux s'en approchent $\left(n^{\circ} 4,21,23\right.$, 24, 13).

Dans le bassin de Montélimar, les pôles attractifs qui structurent le réseau routier sont plus disparates. On note quand même l'importance de Montélimar qui happe une partie des relations est-ouest. Il faut probablement imaginer une traversée du Rhône au niveau de Montélimar et du Teil. La vallée de l'Escoutay à la sortie du Teil permet de rejoindre la cité d'Alba par la voie antonine (Napoli et Rébuffat 1992).

On remarque également au nord de Montélimar que la vallée située entre les massifs de la Givaude et de la Montagne a sûrement été intensément parcourue, et a très tôt concurrencé le passage le long du Rhône. Une grande partie des itinéraires relevés lors de l'analyse morphologique s'y dirige.

Le franchissement des collines séparant le nord du bassin valdainais de la vallée de la Drôme paraît varié ; les chemins mis en évidence ne sont pas canalisés par une seule vallée, mais se dispersent sur plusieurs points de passage et aboutissent sur la voie des Alpes au niveau des agglomérations antiques de Crest ou d'Aouste-sur-Sye.

\subsection{Le Rhône}

La trame de communications terrestres que nous avons présentée permet des échanges denses et variés (choix de différents itinéraires en fonction des charges à transporter) ; elle doit être complétée par le transport fluvial. Le Rhône constitue un axe de circulation nord-sud privilégié durant l'Antiquité, comme le montrent les études archéologiques et géoarchéologiques qui concernent les dynamiques territoriales et fluviales liées à ce cours d'eau (Leveau dir. 2000). Il semble que durant l'Antiquité, le fleuve présente entre Lyon et la mer un régime fluvial relativement régulier avec un chenal bien incisé qui facilite la navigation
(Provansal et al. 2000). On note cependant une reprise de l'activité hydrique entraînant des taux de sédimentation élevés et un exhaussement du plancher fluvial dans la moyenne vallée du Rhône, entre la fin du $\mathrm{I}^{\mathrm{er}} \mathrm{s}$. et la fin du $\mathrm{III}^{\mathrm{e}} \mathrm{s}$. de notre ère. La multiplication des crues et le changement de style fluvial présentent une contrainte certaine pour les agglomérations riveraines, mais celles-ci s'en accommodent en aménageant les berges ou en exhaussant les sols d'habitation ( $c f$. Arles, Vienne, Saint-Romain-enGal). L'intérêt que présente la présence du fleuve pour ces villes est largement supérieur aux contraintes qu'il véhicule.

Outre le développement de centres urbains en contact avec le Rhône, la navigation fluviale est également perçue par les matériaux (pierre du Midi, marbre de Carrare, lingots de métal issus de la Montagne Noire) et les produits importés (amphores vinaires et à huile) que l'on retrouve dans ces agglomérations (Fiches et Christol 2000). La présence régulière d'ateliers de potiers en bordure du fleuve témoigne aussi du débouché commercial que pouvait offrir le Rhône. Enfin, les monuments à caractère votif ou funéraire qui jalonnent le cours du fleuve illustrent eux aussi l'importance de cette voie d'eau dans la circulation des biens et des personnes et la mise en scène du paysage.

Nous avons peu d'éléments sur la fréquentation nautique du Rhône durant l'Antiquité, mais les données pour la période médiévale montrent son importance pour le transport du sel, du bois, des céréales et des tuiles. Le relevé des comptes journaliers du péage de Baix en 14481450 indique la régularité des passages au fil des ans (autour de 130 bateaux) mais sur une période comprise de mars à novembre (Denel 1970 : 290). Par ailleurs, les compagnies de haleurs sont très répandues à la même époque le long de la vallée du Rhône (Rossiaud 1978), le halage se faisant exclusivement par traction humaine « halage au col » jusque vers la fin du $\mathrm{XV}^{\mathrm{e}} \mathrm{s}$. (Rossiaud 1978).

Les différentes voies nord-sud mises en évidence par l'analyse morphologique montrent qu'il était possible de choisir une variété d'itinéraires pendant les périodes où le Rhône était difficilement navigable (variations saisonnières) et de maintenir de façon constante les relations commerciales. En effet, hormis la voie d'Agrippa dont le tracé est bien avéré, on note la présence de plusieurs « itinéraires bis » ou de diverticules lors de passages de reliefs.

\section{Conclusion}

Cet article s'est attaché à faire vivre un peu plus le réseau routier antique du Tricastin et de la Valdaine en proposant d'identifier un certain nombre d'itinéraires. La méthode du tri morphologique, mise au point par Eric 
Vion, fait ressortir un véritable tissu de chemins dont on peut attribuer le fonctionnement durant la période romaine. Les observations archéologiques réalisées pour la plupart lors des travaux du TGV-Méditerranée, ont permis d'attester la romanité des axes recoupés et de donner corps à l'analyse morphologique.
On peut donc désormais raisonner sur un réseau routier et non plus seulement sur une voie publique connue par les textes et les inscriptions.

Cécile JUNG - INRAP Méditerranée, UMR 5140 « Archéologie des sociétés méditerranéennes, Lattes-Montpellier.

\section{BIBLIOGRAPHIE}

Allimant 1994 : ALLIMANT (A.) - Étude de la collection Vallentin du Cheylard, le sanctuaire d'Allan, In : ODIOT (T.), Occupation des sols dans le Tricastin de la conquête romaine au début du Moyen Âge, Programme collectif de recherche, rapport intermédiaire tap., S.R.A. Rhône-Alpes, 1994.

Archaeomedes 1998 : ARCHAEOMEDES - Des oppida aux métropoles. Archéologues et géographes en vallée du Rhône, collection villes, Anthropos, Paris, 1998.

Barruol 1969 : BARRUOL (G.) - Les peuples préromains du sud-est de la Gaule, 1969.

Barruol 1972 : BARRUOL (G.) - À la recherche d'Aeria, ville celtique, Latomus XXXI, 1972, p. 971-996.

Berger, Jung et coll. 1999 : BERGER (J.-F.), JUNG (C.) et coll. Lots 11,12, 13, 21 Rapport Fossés. Opération transversale, AFANTGV Ligne 5 -Secteur II : Valence-Avignon, Rapport de fouille, 2 volumes, rapport de fouille, tap., S.R.A. Rhône-Alpes et S.R.A. Provence Côte d'Azur, 1999.

Bois 1993 : BOIS (M.) - Le sud du département de la Drôme entre le $X^{e}$ et le XIII ${ }^{e}$ siècle, l'organisation du terroir, fortifications et structures d'habitat, 3 volumes, thèse de doctorat tap., Université de Provence, Aix-en-Provence, 1993.

Boisse 1968 : BOISSE (C.) - Le Tricastin des origines à la chute de L'Empire romain, SOREPI, Valence, 1968.

Broise 1984 : BROISE (P.) - Agglomérations rurales gallo-romaines en Vaucluse, RANarb, 17, 1984, p. 257-271.

Chapotat 1981 : CHAPOTAT (G.) - La voie protohistorique sud de la croisée de Vienne. Essai de reconstitution de son tracé jusqu'à Marseille, $R A E$, 32, fasc. 3-4, 1981, p. 83-91.

Chouquer 1994 : CHOUQUER (G.) - Etude morphologique du cadastre B d'Orange, In : FAVORY (F.) et FICHES (J.-L.), Les campagne de la France méditerranéennes dans l'Antiquité et le haut Moyen Age, Études micro-régionales, DAF n²4, Maison des Sciences de l'Homme, Paris 1994, p. 51-55.

Chouquer 1995 : CHOUQUER (G.) - Le plan cadastral « B » d'Orange», In : Van der LEEUW (S.) (dir.), Understanding the natural and anthropogenic causes of soil degradation and desertification in the mediterranean basin, Archaeomedes Project, volume 3, partie 2, Inédit, 1995, p. 215-234.

Chouquer et Jung 1996 : CHOUQUER (G.) et JUNG (C.) - TGV LN5 Méditerranée, Étude des formes du paysage par carto-et photo-interprétation, département de la Drôme, Lots 11, 12, 13, Document Final de Synthèse tap., S.R.A. Rhône-Alpes, 1996.
Christol et Fiches 2000 : CHRISTOL (M.) et FICHES (J.-L.) - Le Rhône : batellerie et commerce dans l'Antiquité, Gallia, 56, 2000, p. 141-155.

Denel 1970 : DENEL (F.) - La navigation sur le Rhône au XVe siècle d'après les registres de péage de Baix, Annales du Midi, tome 82, juil-sept 1970, p. 287-298.

Desjardins 1893 : DESJARDINS (E.) - Géographie historique et administrative de la Gaule romaine. Les sources de la topographie comparée, Tome IV, Paris, 1993.

Estienne 1553 : ESTIENNE (Ch.) - Guide des chemins de France de 1553, édité par J. Bonnerot, 1936.

Henry et Linossier 1997 : HENRY (E.) et LINOSSIER (M.) - Lot 13, La Garde-Adhémar, Surel, Drôme, AFAN-TGV Ligne 5Secteur II : Valence-Avignon, rapport d'évaluation tap., S.R.A. Rhône-Alpes, 1997.

Henry 2002 : HENRY (E.) - L'établissement antique de Surel à La Garde-Adhémar (Drôme), fiche n83. In : Archéologie du TGV Méditerranée, fiches de synthèse, tome 3, Antiquité, Moyen Âge, Epoque moderne, MAM, 10, 2002, p. 781-785.

Jung et al. 1998 : JUNG (C.) et al. - Programme H11 Tricastin. Rapport final tap., S.R.A. Rhône-Alpes, 1998.

Jung 1999 : JUNG (C.) - Morphogenèse, fonctions et évolution de la centuriation $B$ d'Orange et essai de restitution diachronique des paléopaysages du Tricastin (Drôme-Vaucluse), thèse, Tours, 1999, 2 volumes.

Leveau dir. 2000 : LEVEAU (P.) (dir.), Le Rhône romain, dossier Gallia, 56, 2000, p. 1-175.

Leveau à paraître : LEVEAU (P.), Les franchissements du Rhône du Lac Léman à la Méditerranée dans l'Antiquité, entre les contraintes techniques et géographie de la circulation. Actes du colloque national Les ponts routiers en Gaule romaine, Pont du Gard 8-11 octobre 2008, RANarb, à paraître.

Meffre et Ballais 1996 : MEFFRE (J.-C.) et BALLAIS (J.-L.) - Le cadastre B d'Orange et la géoarchéologie du cours inférieur de l'Aigues et du bois d'Uchaux. Pour une nouvelle localisation d'un fragment du plan antique. In : CHOUQUER (G.) (dir.) : Les formes du paysage, tome 2, Errance, Paris, 1996, p. 67-80.

Mège 1986 : MEGE (J.-C.) - Le pagus Aletanus, problème de géographie historique. In :MEGE (J.C) et DESAYE (H.) : Épigraphie du Midi de la Drôme, Revue drômoise, 439, 1986, p. $10-22$. 
Mège et Le Rouzic 1995 : MEGE (J.-C.) et LE ROUZIC (R.-M.) Rapport de prospection, Canton de Grignan, rapport tap., S.R.A. Rhône-Alpes, 1995.

Monguilan 1994 : MONGUILAN (L.) - La prospection aérienne des cadastres antiques. In : FAVORY (F.) et FICHES (J.-L.) : Les campagne de la France méditerranéennes dans l'Antiquité et le haut Moyen Âge, Etudes micro-régionales, DAF n ${ }^{\circ} 42$, Paris Maison des Sciences de l'Homme, 1994, p. 146-150.

Napoli et Rebuffat 1992 : NAPOLI (J.) et REBUFFAT (R.) - Les milliaires ardéchois d'Antonin le Pieux, Gallia, 49, 1992, p. 51-79.

Ode 1995 : ODE (B.) - Saint-Saturnin, un site fortifié de l'Antiquité Tardive, Recherches Donzéroises, ${ }^{\circ}$ 21, 1995, p. 1-14.

Ode 1996 : ODE (B.) - Le défilé de Donzère de la fin de l'Antiquité aux débuts du Moyen Âge. Recherches Donzéroises, n 22, 1996, p. 1-22.

Odiot 1994 : ODIOT (T .) - Habitats, sols et cadastres dans le Tricastin. In : FAVORY (F.) et FICHES (J.-L.) : Les campagne de la France méditerranéennes dans l'Antiquité et le haut Moyen $\hat{A} g e$, Etudes micro-régionales, DAF n ${ }^{\circ} 42$, Maison des Sciences de l'Homme, Paris, 1994, p. 73-107.

Odiot 1996 : ODIOT (T .) - Le Molard, Formes de l'habitat rural en Gaule Narbonnaise, spécial villa romaine, $\mathrm{n}^{\circ} 3$, Editions APDCA, Sophia-Antipolis, 1996.

Peloux 1993 : PELOUX (O.) - Les voies de Donzère pendant la période moderne et contemporaine, Les Recherches Donzéroises, 19, 1993.

Piganiol 1962 : PIGANIOL (A.) - Les documents cadastraux de la colonie romaine d'Orange, XVI ${ }^{\mathrm{e}}$ supplément à Gallia, CNRS, Paris, 1962.

Poinsart 1992 : POINSART (D.) - Effets des aménagements fluviaux sur les débits liquides et solides. L'exemple du Rhône dans les plaines de Miribel-Jonage et de Donzère-Mondragon, thèse tap., Université Lyon III, 1992.

Provansal et al. 2000 : PROVANSAL (M.), BERGER (J.-F.), BRAVARD (J.-P.), SALVADOR (P.-G.), ARNAUD-FASSETTA (G.), BRUNETON (H.), VÉROT-BOURRÉLY (A.) - Le régime du Rhône dans l'Antiquité et au haut moyen âge, Gallia, 56, 2000, p. 13-32.

Rébuffat 1995 : REBUFFAT (R.) - Un milliaire romain neuf, Ardèche Archéologie, 12, 1995, p. 49-58.

Rochetin 1883 : ROCHETIN - La viabilité romaine dans le département de Vaucluse, Avignon, 1883.
Rossiaud 1978 : ROSSIAUD (M.) - Les hâleurs du Rhône au $\mathrm{XIV}^{\mathrm{e}}$ s., Annales de Bretagne et des pays de l'Ouest, 85-2, 1978, p. 283-304.

Rossiaud 2007 : ROSSIAUD (M.) - Le Rhône au Moyen Âge, Paris, Aubier, Collection historique, 2007, 648 p.

Salviat 1985 : SALVIAT (F.) - Le cadastre B d'Orange, la route antique au sud de Montélimar, le problème de Dourion et le cours inférieur de la Berre, RANarb , 18, 1985, p. 277-287.

Sautel 1957 : SAUTEL (J.) - La carte archéologique de la Gaule romaine, Département de la Drôme, 1957, p. 37.

Tourrenc 1971 : TOURRENC (M.-S.) - Malataverne, Informations Archéologiques, Gallia , 29, fasc.2, 1971, p. $434-435$.

Vallentin 1880 : VALLENTIN (F.) - La voie d'Agrippa de Lugdunum au rivage massaliote, Revue du Dauphiné et $d u$ Vivarais , 4, 1880, p. 373-393.

Van der Leeuw, Favory et Fiches (dir.) 2003 : VAN DER LEEUW (S.), FAVORY (F.), FICHES (J.-L.) (dir.) - Archéologie et systèmes socio-environnementaux. Etudes multiscalaires sur la vallée du Rhône dans le programme ARCHAEOMEDES, CRA 27, CNRS éditions, 2003.

Vermeulen 1997 : VERMEULEN (C.) - Lot 12, Montboucher, les Hayes, Drôme, AFAN-TGV Ligne 5-Secteur II : Valence-Avignon, rapport d'évaluation tap., S.R.A. Rhône-Alpes, 1997.

Vermeulen 2002 : VERMEULEN (C.) - La voie antique des Hayes (Montboucher-sur-Jabron, Drôme) reliant Montélimar et Aouste-sur-Sye. fiche $\mathrm{n}^{\circ}$ 77. In : Archéologie du TGV Méditerranée, fiches de synthèse, tome 3, Antiquité, Moyen Âge, Epoque moderne, MAM, 10, 2002, 735-740.

Vermeulen 2002b : VERMEULEN (C.) - Le chemin médiéval de Gontardin ou Costardin sur le sites des Hayes à Montboucher-sur-Jabron, (Drôme). fiche $\mathrm{n}^{\circ} 78$. In : Archéologie du TGV Méditerranée, fiches de synthèse, tome 3, Antiquité, Moyen Âge, Epoque moderne, MAM, 10, 2002, p. 741-743.

Vion 1989 : VION (E.) - L'analyse archéologique des réseaux routiers : une rupture méthodologique, des réponses nouvelles, Paysage Découverts, 1, 1989. 